KRK 4253

CNEANT-33/86

Juni 1987

\title{
New Determination of the $\mathrm{UO}_{2} /$ Zircaloy Reaction Kinetics and Calculation of the Oxygen Diffusion Coefficients
}

\author{
P. Hofmann, H. Uetsuka \\ Institut für Material- und Festkörperforschung \\ Projektgruppe LWR-Sicherheit \\ E. Garcia, A. Denis \\ Departamento de Materiales, CNEA/CAC, \\ Buenos Aires, Argentina
}

Kernforschungszentrum Karlsruhe 



\title{
Kernforschungszentrum Karlsruhe Institut für Material- und Festkörperforschung \\ Projektgruppe LWR-Sicherheit \\ Departamento de Materiales, CNEA/CAC, \\ Buenos Aires, Argentina
}

KfK 4253

CNEA NT-33/86

\section{New Determination of the $\mathrm{UO}_{2} /$ Zircaloy Reaction Kinetics and Calculation of the Oxygen Diffusion Coefficients}

\author{
P. Hofmann \\ H. Uetsuka* \\ E. Garcia \\ A. Denis
}

*JAERI, Tokai-mura, Japan

Kernforschungszentrum Karlsruhe $\mathrm{GmbH}$, Karlsruhe 
Als Manuskript vervielfältigt

Für diesen Bericht behalten wir uns alle Rechte vor

Kernforschungszentrum Karlsruhe $\mathrm{GmbH}$

Postfach 3640, 7500 Karlsruhe 1

\section{ISSN 0303-4003}




\section{Summary}

The results of the isothermal $\mathrm{UO}_{2} /$ Zircaloy interaction experiments were corrected with respect to the actual annealing temperature and the reaction time. This was done by comparison of the $\mathrm{ZrO}_{2}$ and $a-\operatorname{Zr}(\mathrm{O})$ reaction layer thicknesses of the $\mathrm{UO}_{2} /$ Zircaloy fuel rod segments, which reacted under oxidizing conditions, with that of Zircaloy cladding oxidation experiments performed in a tube furnace under well controlled temperature conditions. The reactions which took place during the heatup and cooldown period were taken into consideration by the determination of a so-called equivalent isothermal annealing time which was added to the actual isothermal annealing time. The resulting new Arrhenius equations, describing the growth rate of the various $\mathrm{UO}_{2} /$ Zircaloy interaction layers, indicate smaller rates below $1300^{\circ} \mathrm{C}$ and higher rates above about $1300^{\circ} \mathrm{C}$ compared to the uncorrected data. The growth rates for the external $\mathrm{ZrO}_{2}$ and $a-\operatorname{Zr}(\mathrm{O})$ reaction layers remained unchanged.

The corrected Arrhenius equations were then used to determine the effective oxygen diffusion coefficient in the various reaction layers. Although certain difficulties arose in the calculations for the high temperature range $\left(>1300{ }^{\circ} \mathrm{C}\right)$, a good agreement between the experimental data and the results of the model was finally achieved using the new effective oxygen diffuson coefficients. The Arrhenius equations for the oxygen diffusion coefficients along with the functions fitted for the oxygen concentration at the phase boundaries also allow the calculation of the $\mathrm{UO}_{2}$ /Zircaloy interactions during temperature transients.

This work was performed within the frame of the German/Argentine Cooperation in the field of peaceful uses of nuclear energy. The conduct and evaluation of the experiments and the correction of the annealing temperature and time was done at the Kernforschungszentrum Karlsruhe. The determination of the effective oxygen diffusion coefficients and the oxygen concentration at the phase boundaries was carried out at the Centro Atomico Constituyentes in Buenos Aires. 


\section{Neue Bestimmung der $\mathrm{UO}_{2}$ /Zircaloy Reaktionskinetik und Berechnung der Sauerstoff- Diffusionskoeffizienten}

\section{Zusammenfassung}

Die Versuchsergebnisse der isothermen $\mathrm{UO}_{2}$ /Zircaloy Reaktionsexperimente wurden im Hinblick auf die tatsächliche Glühtemperatur und Reaktionszeit korrigiert. Dies erfolgte durch einen Vergleich der $\mathrm{ZrO}_{2}$ - und a-Zr(O)-Schichtdicken von $\mathrm{UO}_{2}$ /Zircaloy-Versuchsproben, die unter oxidierenden Bedingungen geglüht wurden, mit den Schichtdicken von Zircaloy-Oxidationsexperimenten, die unter gut kontrollierten Temperaturbedingungen in einem Rohrofen durchgeführt wurden. Die Reaktionen, die während der Aufheiz- und Abkühlzeit stattfanden, wurden durch die Bestimmung einer equivalenten isothermen Glühzeit, die zu der tatsächlichen Glühzeit addiert wurde, berücksichtigt. Die resultierenden neuen Arrhenius-Gleichungen, die die Wachstumsraten der verschiedenen $\mathrm{UO}_{2}$ /Zircaloy-Reaktionsschichten beschreiben, ergeben kleinere Wachstumsraten unterhalb $1300{ }^{\circ} \mathrm{C}$ und größere oberhalb $1300{ }^{\circ} \mathrm{C}$ im Vergleich zu den nicht korrigierten Daten. Die Wachstumsraten für die äuBeren $\mathrm{ZrO}_{2^{-}}$und $\mathrm{a}-\mathrm{Zr}(\mathrm{O})$ Schichten bleiben unverändert.

Die korrigierten Arrhenius-Gleichungen wurden dann benutzt, die effektiven Sauerstoff-Diffusionskoeffizienten in den verschiedenen Reaktionszonen zu bestimmen. Obwohl bei der Berechnung einige Schwierigkeiten bei hohen Temperaturen $\left(>1300{ }^{\circ} \mathrm{C}\right.$ ) auftraten, konnte schließlich eine gute Übereinstimmung zwischen den Versuchsergebnissen und den Modellberechnungen unter Benutzung der neuen effektiven Sauerstoff-Diffusionskoeffizienten erreicht werden. Die Arrhenius-Gleichungen für die Sauerstoff-Diffusionskoeffizienten, zusammen mit den angepaßten Funktionen für die Sauerstoff-Konzentration an den Phasengrenzen, erlauben auch die Bestimmung der $\mathrm{UO}_{2}$ /Zircaloy-Reaktionsschichten bei temperaturtransienten Experimenten.

Diese Arbeit entstand im Rahmen der deutsch/argentinischen Zusammenarbeit auf dem Gebiet der friedlichen Nutzung der Kernenergie. Die Durchführung und Auswertung der Experimente sowie die Temperatur- und Zeitkorrektur der Versuchsergebnisse erfolgte im Kernforschungszentrum Karlsruhe. Die Bestimmung der effektiven Sauerstoff-Diffusionskoeffizienten und der Sauerstoff-Konzentrationen an den Phasengrenzen wurden im Centro Atomico Constituyentes in Buenos Aires durchgeführt. 


\section{Content}

Page

\section{Summary}

1. Introduction

2. Experimental Results 2

2.1 Procedure of the Experimental Data Correction 2

2.2 Experimental Results and Discussions 3

$\begin{array}{ll}2.3 \text { Conclusions } & 10\end{array}$

3. Theoretical Results 11

3.1 Calculation of the Oxygen Diffusion Coefficients 11

3.2 Oxygen Concentration at the Phase Boundaries 13

3.3 Oxygen Diffusion Coefficients in the Various Reaction Zones 15

3.4 Calculation Method 16

$\begin{array}{ll}3.5 & \text { Results and Discussion } \\ & 18\end{array}$

$\begin{array}{ll}3.6 \text { Conclusions } & 20\end{array}$

$\begin{array}{ll}\text { 4. Acknowledgement } 20 & 20\end{array}$

5. References 21

List of Tables $\quad 24$

List of Figures $\quad 25$ 


\section{Introduction}

Evaluating severe fuel damage (SFD) accidents of light water reactors (LWR) requires detailed knowledge of the chemical interactions and reaction kinetics between $\mathrm{UO}_{2}$ fuel and Zircaloy-4 (Zry) cladding as well as between steam or oxygen and Zry at high temperatures. Extensive out-of-pile $\mathrm{UO}_{2} / Z$ ry interaction experiments have been performed at temperatures ranging from 900 to $1700^{\circ} \mathrm{C}$ in the high temperature/high pressure equipment MONA under inert gas ( $\mathrm{Ar}$ ) conditions [1,2] and oxidizing conditions $\left(\mathrm{Ar}+25\right.$ vol. \% $\left.\mathrm{O}_{2}\right)[3,4,12]$. The results obtained to date have been used in developing and verifying computer codes describing the chemical interactions $[3,5,6,12]$.

However, two non-negligible problems are encountered in both the experimental MONA data and the derived reaction kinetics. The first problem is the inaccuracy of temperature measurement. This can be readily discerned from the difference in the data between two series of tests $(A)$ and $(B)$ performed at the same nominal temperature of $1600^{\circ} \mathrm{C}$ in the MONA equipment under inert gas conditions described in [1,2]. In the MONA apparatus $[1,2,3,4,12]$ non-contact temperature measurements were performed using an infrared and an emissivityinsensitive dual-wavelength pyrometer. In general, it is difficult to perform accurate temperature measurements at high temperatures. Therefore, when possible, the measured temperature should be checked by an independent method. In the case of the isothermal oxidation of Zry, it is possible to determine the cladding temperature from the time at temperature and the thickness of the oxide $\left(\mathrm{ZrO}_{2}\right)$ layer which forms on the surface of the tube specimen. A check by this method was performed in previous work [7] and the evident difference between pyrometrically measured and estimated temperatures was demonstrated. The second problem is in the evaluation method of the isothermal annealing time. The heat-up period and the cool-down period are included in the overall reaction but are not considered in the isothermal reaction time. However, a certain extent of reaction is expected to occur in both the heatup and cool-down periods. These reactions should not be neglected, especially in the case of short-time isothermal testing. Therefore, the so-called isothermal annealing time requires an appropriate correction. In the evaluation of the MONA data performed up to now, the heat-up and cool-down periods have not been taken into consideration. 
In this report, the experimental MONA data [1] are re-evaluated by considering the two problems mentioned above and new reaction kinetics data are derived (Arrhenius equations) which will then be used for the determination of the oxygen diffusion coefficients in the various reaction zones.

To perform calculations concerning the growth of the various $\mathrm{UO}_{2} / \mathrm{Zry}$ interaction layers, knowledge of the oxygen diffusion coefficients is necessary. These can be determined using the experimental results of the $\mathrm{UO}_{2} / \mathrm{Zry}$ interaction experiments. The results of the first calculations, using the uncorrected experimental data, are published in [5]. Since the $\mathrm{UO}_{2} / \mathrm{Zry}$ interaction kinetics data were corrected with respect to the annealing temperature and reaction time also new calculations have been necessary to determine the oxygen diffusion coefficients in the various reaction zones.

\section{Experimental Results}

\subsection{Procedure of the Experimental Data Correction}

During the interaction between $\mathrm{UO}_{2}$ and Zry the following reaction layers were formed on the cladding inside and outside surface in a particular sequence at all examined temperatures and reaction times $[1,2,3,12]$ :

$$
\left[a-\mathrm{Zr}(\mathrm{O})_{\mathrm{a}}+(\mathrm{U}, \mathrm{Zr})\right] \rightarrow(\mathrm{U}, \mathrm{Zr}) \rightarrow \mathrm{a}-\mathrm{Zr}(\mathrm{O})_{\mathrm{b}} \rightarrow \operatorname{prior} \beta-\mathrm{Zry} \rightarrow \mathrm{a}-\mathrm{Zr}(\mathrm{O})_{c} \rightarrow \mathrm{ZrO}_{2}
$$

The $\mathrm{a}-\mathrm{Zr}(\mathrm{O})_{\mathrm{C}}$ and $\mathrm{ZrO}_{2}$ layers were formed on the cladding outside surface only in experiments under oxidizing conditions [3,12]. As shown in Figure 1, zone 1 is defined as the thickness of the $\left[a-\operatorname{Zr}(O)_{a}+(U, Z r)\right]$ layer, zone $I I$ as the thickness of zone I plus that of the $(\mathrm{U}, \mathrm{Zr})$ alloy layer, zone III as the thickness of zone II plus that of the $a-\operatorname{Zr}(O)_{b}$ layer, zone IV as the thickness of $a-\operatorname{Zr}(O)_{c}$ plus that of the $\mathrm{ZrO}_{2}$ layer, and zone $\mathrm{V}$ as the thickness of the $\mathrm{ZrO}_{2}$ layer.

The sequence of the data correction is described below and schematically shown in Fiqure 2.

(a) A simple method of temperature-time normalization of the experiments, described in [7], is used to estimate the equivalent isothermal annealing time of each test. The applicability of this method is verified by comparing the reaction layer thicknesses measured in the MONA temperature 
transient experiments $[8,12]$ with the values calculated by the kinetics equation for the estimated equivalent isothermal annealing times.

(b) Reliable kinetics equations for the growth rates of zones IV and $V$ were obtained in the Zry-oxidation experiments [7]. These equations are used to reevaluate and correct the nominal test temperatures of the MONA experiments under oxidizing conditions in which the thicknesses of zones IV and $V$ were measured $[3,4,12]$, using the equivalent isothermal annealing time determined in (a) which also includes the heatup and cooldown. The reation kinetics equations for the growth rates of zone I, II, III, IV and V are then determined on the basis of the corrected temperatures.

(d) The final stage of these procedures is to correct the nominal test temperatures of the MONA experiments under inert gas conditions [1,2]. In these series of experiments Zones IV and V did not form. Consequently, reliable kinetics equations obtained in the Zry-cladding-oxidation experiments [7] cannot be applied for this correction. However, the kinetics equations for the growth rate of zones I, II and III, which are established for the MONA data under oxidizing conditions, can be applied for the correction, since the essentially same interaction between $\mathrm{UO}_{2}$ and Zry is expected to occur in both MONA experiments under inert gas and oxidizing conditions at short annealing times.

\subsection{Experimental Results and Discussion}

In the MONA experiments under oxidizing conditions [3,4,12], the Zry-4 cladding specimens are tested in a gas mixture of 25 vol. $\% \mathrm{O}_{2}+75 \mathrm{vol} . \% \mathrm{Ar}$ and the test temperature is measured with an infrared pyrometer. Accurate high temperature measurements are difficult and, when possible, the measured temperatures should be checked by an independent method. In the case of the isothermal oxidation of Zry, it is possible to determine the specimen temperature for a given time at temperature from the thickness of the oxide layer which forms on the specimen surface. The kinetics for the $\mathrm{ZrO}_{2}$ oxide layer growth in a mixture of 25 vol. $\% \mathrm{O}_{2}+75$ vol. $\%$ Ar was accurately determined in a tube furnace for the temperature range from 900 to $1500^{\circ} \mathrm{C}$ and the results are described in [7]. The kinetics equations obtained in that work [7] for the growth of the $\mathrm{ZrO}_{2}$ layer thickness are as follows: 


$$
\begin{array}{ll}
K_{\delta}=21.52 \exp (-222,682 / R T) & \text { for } 900-1099^{\circ} \mathrm{C} \\
K_{\delta}=8.27 \cdot 10^{-4} \exp (-107,230 / R T) & \text { for } 1100-1199^{\circ} \mathrm{C} \\
K_{\delta}=6.14 \cdot 10^{-3} \exp (-131,775 / R T) & \text { for } 1200-1299^{\circ} \mathrm{C} \\
K_{\delta}=0.259 \exp (-180,709 / R T) & \text { for } 1300-1399^{\circ} \mathrm{C} \\
K_{\delta}=158.2 \exp (-269,890 / R T) & \text { for } 1400-1499^{\circ} \mathrm{C}
\end{array}
$$

The units of the parabolic rate constants, $\mathrm{K}_{\delta}$, are $\mathrm{cm}^{2} / \mathrm{s}$, the universal gas constant $R=8.314 \mathrm{~J} / \mathrm{mol} \cdot \mathrm{K}$ and $\mathrm{T}$ is the absolute temperature in $\mathrm{K}$.

In performing the isothermal annealing tests the heat-up and cool-down are included in the overall annealing. Therefore, the reaction occurring during heatup and cooldown should be taken into consideration. There are two possible methods for this correction. The first is to estimate the equivalent isothermal annealing time by a temperature - time normalization method which is described in detail in [7]. If one assumes that the rate constants for the reaction kinetics between $\mathrm{UO}_{2}$ and $\mathrm{Zry}$ follow an Arrhenius relationship, the equivalent isothermal annealing time at an assigned temperature can be approximately calculated by the following equation:

$$
\begin{aligned}
& t_{e q}=t_{s} \frac{\sum_{i=1}^{n} \exp \left(-Q / R^{T} T i\right)}{\exp \left(-Q / R^{\prime} T_{a s}^{\prime}\right)} \\
& \text { where } t_{e q}=\text { equivalent isothermal annealing time in } s \text { at an assigned } \\
& \text { temperature } T_{\text {as }} \\
& \mathrm{T}_{\mathrm{as}}=\text { assigned temperature in } \mathrm{K} \\
& t_{s}=\text { time step in } s \\
& \mathrm{Q}=\text { activation energy } \\
& \mathrm{R}=\text { universal gas constant, } 8.314 \mathrm{~J} / \mathrm{mol} \cdot \mathrm{K} \\
& \mathrm{Ti}=\text { average temperature at each time step in } \mathrm{K} \text {. }
\end{aligned}
$$

From the results of the MONA experiments $[1,2]$, the $\mathrm{UO}_{2} / 2$ ry reaction kinetics seem to obey an Arrhenius relationship. Therefore, this assumption is probably appropriate. The estimation by this method involves two problems in the present case of correction, which are described below. 
a) There are only preliminary empirical equations available from own results describing the reaction between $\mathrm{UO}_{2}$ and $Z$ ry in a wide temperature range. Therefore we must assume an average value of activation energy $(Q)$ for the calculation.

b) The temperature - time curves in the MONA experiments were not recorded very precisely so that it is difficult to use such curves as a reference curve for normalization. Therefore, we must assume an ideal transient curve of heat-up $(10 \mathrm{~K} / \mathrm{s})$ and cool-down $(5 \mathrm{~K} / \mathrm{s})$ and use it for the temperature - time normalization [see figure 2 in 1 or 2].

However, these two problems are not so serious, since a considerable difference of Q-value does not produce a significant change in the calculated results and the temperature control capability of the MONA facility seems to be good enough to neglect the error caused by the second assumption.

The second possible method is to subtract the extent of reaction occurring during heat-up and cool-down from the overall amount of reaction (Overall data - transient data $=$ isothermal data). However, there is a problem also in this method of correction. For example, the heat-up period of the transient does not necessarily give the same amount of influence on the overall reaction extent occurring in the subsequent isothermal annealing period compared to the cooldown period. It seems to be very difficult to compensate the error caused by this problem.

By the first method, the equivalent isothermal annealing time - which causes the same extent of chemical interactions as during the heat-up and cool-down periods of temperature transient experiments - were calculated and listed in Table 1. For these calculations (equation 1) a time step $t_{s}$ of $2 \mathrm{~s}$ was used and an average activation energy of $175 \mathrm{~kJ} / \mathrm{mol}$ was applied [7,10]. This result shows that the temperature transient from $650^{\circ} \mathrm{C}$ up to $1700^{\circ} \mathrm{C}$ and back to $650^{\circ} \mathrm{C}$

$$
650^{\circ} \mathrm{C} 10 \mathrm{~K} / \mathrm{s} 1700^{\circ} \mathrm{C} 5 \mathrm{~K} / \mathrm{s} 650^{\circ} \mathrm{C}
$$

is equivalent to an isothermal annealing of $47.4 \mathrm{~s}$ at $1700{ }^{\circ} \mathrm{C}$ (table 1) as schematically shown in Figure 3. 
The nominal test temperatures of the MONA experiments under oxidizing conditions can now be corrected using the kinetics data (A) and the estimated equivalent isothermal annealing times (table 1). The thickness of the oxide layer is described by a parabolic expression of the form (2):

$$
\begin{aligned}
& \delta^{2}=\mathrm{K}_{\delta} \mathrm{t} \\
& \text { where } \delta \text { = thickness of the oxide layer in } \mathrm{cm} \\
& \mathrm{t}=\text { oxidation time in } \mathrm{s} \\
& \mathrm{K}_{\delta}=\text { parabolic rate constant for } \mathrm{ZrO}_{2} \text { oxide layer growth. }
\end{aligned}
$$

The equations describing the temperature dependence of the parabolic rate constant for the oxide layer growth are listed under (A). By using this set of equations and the time at temperature (estimated equivalent annealing time), the actual isothermal annealing temperature can be calculated from the measured thickness of the $\mathrm{ZrO}_{2}$ oxide layer. The temperatures estimated in this way are listed in Table 2 together with the experimental data of the $\mathrm{UO}_{2} / \mathrm{Zry}$ interaction experiments.

The thickness of each zone measured in the MONA temperature transient experiments $[8,12]$ and the corresponding values of each zone calculated on the basis of the obtained reaction kinetics (Tables 4 and 5 ) are listed in Table 3 . The difference between the measured zone thickness (m.t.) and the calculated value (c.v.) is caused by some factors. The inaccuracy of the MONA actual test temperature, which differs somewhat from the nominal annealing temperature, can be one of the most influential factors. Equivalent isothermal annealing times, estimated on the basis of the assumption above, must include a certain extent of error. Moreover, in the calculation the applicable temperature and time range of the kinetics equations was neglected. This can also produce a nonnegligible error. The following tendency is generally seen in Table 3.

$$
\begin{array}{ll}
\text { m.t. }>\text { c.v. } & \text { at } 1100,1200^{\circ} \mathrm{C} \\
\text { m.t. } \simeq \text { c.v. } & \text { at } 1300,1400^{\circ} \mathrm{C} \\
\text { m.t. }<\text { c.v. } & \text { at } 1500,1600,1700^{\circ} \mathrm{C}
\end{array}
$$

m.t. = measured thickness, c.v. = calculated value

This may suggest the underestimation of the annealing temperature in the MONA experiments at 1100 and $1200{ }^{\circ} \mathrm{C}$ and its overestimation at 1500 to 
$1700^{\circ} \mathrm{C}$. However, the comparable calculated and the measured reaction layer thicknesses in Table 3 probably prove the applicability of the time - temperature normalization method.

The parabolic rate law constants for zones I- $V$ in the MONA experiments $[3,4]$ under oxidizing conditions are listed in Table 4 . These constants were calculated by the method of least squares on the basis of the estimated equivalent isothermal annealing times (Table 1). Figure 4 is an Arrhenius plot of the parabolic rate constants, $K_{p}\left(x^{2} / t\right)$, versus reciprocal temperature $1 \pi$; the determined temperature dependent Arrhenius correlations are listed in Table 5. Based on the three kinetics equations for zone I, II and III in Table 5, it is possible to evaluate and correct the pyrometrically measured nominal test temperatures in the MONA experiments performed in Ar [1,2].

The good fit of the data points to the regression lines in Fig. 4 suggests the high reliability of the estimation based on the kinetics equations for $K_{p}(I)$ and $K_{p}$ (II). Such estimation on $K_{p}(I)$ and $K_{p}(I I)$ is valid for the temperature range 1100 to $1400^{\circ} \mathrm{C}$. The estimation at $1000^{\circ} \mathrm{C}$ can be performed only for $K_{p}(I I I)$. And the extrapolated values of $K_{p}(1), K_{p}(I I)$ and $K_{p}$ (III) are probably applicable for the estimation above $1500^{\circ} \mathrm{C}$. According to the previous reports [1,2], zone I can be well defined metallographically. However, the boundary between the $(U, Z r)$ layer and $\mathrm{a}-\mathrm{Zr}(\mathrm{O})_{\mathrm{b}}$ layer can be very irregular, especially at very high temperatures ( $1400^{\circ} \mathrm{C}$ ). This means a low reliability of estimation on $K_{p}$ (II) and $K_{p}$ (III) in the high temperature region above $1400^{\circ} \mathrm{C}$. Therefore, it is appropriate to estimate and correct the nominal test temperatures in the MONA experiments by using the kinetics equations for $K_{p}(I)$ in the temperature range above $1400^{\circ} \mathrm{C}$.

The MONA data and the estimated annealing temperatures determined from the thickness of each zone are listed in Table 6 and the average value of the estimated temperatures and finally corrected temperatures are listed in Table 7. The finally corrected actual temperatures between 1100 and $1300{ }^{\circ} \mathrm{C}$ are the average of three estimated temperatures at each temperature level. At $1400^{\circ} \mathrm{C}$ and higher temperatures only the data of reaction zone I were used due to the reasons described above.

Figure 5 shows the correlation between the nominal test temperatures in the MONA experiments [1,2] and the corrected actual temperatures. This clearly shows the underestimation of the temperature in the range below $1200^{\circ} \mathrm{C}$ and 
the overestimation above $1300{ }^{\circ} \mathrm{C}$. The parabolic rate law constants $\left(K_{p}: \mathrm{cm}^{2 / 5}\right)$ for zones I, II and III in the MONA experiments [1,2] in Ar are listed in Table 8. Both the original $K_{p}$ values [1] and the corrected values which are calculated by considering the estimated equivalent annealing times (Table 1) are listed in Table 8 . The original values are slightly larger than the corrected values except for $1500^{\circ} \mathrm{C}$. At $1500^{\circ} \mathrm{C}$ the original values are smaller than the corrected ones, due to the different number of the data points. An additional data set, the results of $W$-marker specimens [1], is taken into account in the correction at this temperature.

Figure 6 is an Arrhenius plot of the new parabolic rate constants versus reciprocal temperature. The determined temperature dependent correlations are as follows:

$$
\begin{aligned}
& K_{p}(1)=1.04 \cdot 10^{3} \exp (-310,395 / R T) \\
& K_{p}\left(\text { II) }=7.54 \cdot 10^{3} \exp (-327,546 / R T)\right. \\
& K_{p} \text { (III) }=1.07 \cdot 102 \exp (-244,678 / R T) \text {. }
\end{aligned}
$$

The rate constant, $K_{p}$, for zones IV and $V$ are [7]:

$$
\begin{aligned}
K_{p}(\text { IV }) & =14.96 \exp (-207,521 / R T) \text { for } 900-1099^{\circ} \mathrm{C} \\
& =1.549 \exp (-181,885 / R T) \text { for } 1100-1400^{\circ} \mathrm{C} \\
K_{p}(V) & =\operatorname{see}(A), \text { page } 4 .
\end{aligned}
$$

The units of the parabolic rate constants, $K_{p}$, are $\mathrm{cm}^{2} / \mathrm{s}$, the universal gas constant $R=8.314 \mathrm{~J} / \mathrm{mol} \cdot \mathrm{K}$ and $\mathrm{T}$ is the absolute temperature in $\mathrm{K}$.

In the previous reports $[1,2]$ relating to the MONA experiments in Ar, the following Arrhenius equations of $K_{p}$ are described:

$$
\begin{aligned}
& K_{p}(1)=5.50 \exp (-241,420 / R T) \\
& K_{p}(I I)=0.259 \exp (-172,800 / R T) \\
& K_{p} \text { (III) }=1.62 \exp (-189,120 / R T) \text {. }
\end{aligned}
$$


Between these Arrhenius equations (D) and the corrected new Arrhenius equations (C), significant variations exist in both the pre-exponential and the exponential terms. The corrected rate constants are compared with the previously determined constants in Figure 7. Non-negligible difference is clearly seen in the comparison of each reaction zone.

According to the previously determined equations (D), the apparent activation energy (Q-term) for the growth of zones I, II and III are in the range between 170 and $240 \mathrm{~kJ} / \mathrm{mol}$. These values are comparable to those for the growth of $\mathrm{a}-\mathrm{Zr}(\mathrm{O})$ layer determined in the Zry-Steam (or $\mathrm{O}_{2}$ ) reaction experiments $[7,9,10,11]$.

$\begin{array}{ll}\text { Cathcart et al. [9]: } & 201 \mathrm{~kJ} / \mathrm{mol} \\ \text { Leistikow et al. [10]: } & 182 \mathrm{~kJ} / \mathrm{mol} \\ \text { Urbanic-Heidrick [11]: } & 165 \mathrm{~kJ} / \mathrm{mol} \\ \text { Uetsuka et al. [7]: } & 238 \mathrm{~kJ} / \mathrm{mol}\end{array}$

Therefore, it was concluded in the previous reports that the diffusion of oxygen into the Zircaloy cladding is the rate determining step in the $\mathrm{UO}_{2}$ /Zry reaction.

On the basis of this conclusion both the $\mathrm{Zr}$ and $U$ diffusions in the cladding are neglected and only the diffusion of oxygen is taken into consideration in a few computer codes describing the chemical interactions between $\mathrm{UO}_{2}$ fuel and Zry cladding during severe accidents of LWRs. However, the apparent activation energies estimated in the present paper are 310 and $330 \mathrm{~kJ} / \mathrm{mol}$ for the zones I and 11 , respectively. This probably suggests that the rate determining step in zone I and II is not only the diffusion of oxygen. On the other hand, the activation energy for the zone III was estimated to be about $245 \mathrm{~kJ} / \mathrm{mol}$. This value is obviously small in comparison with those for the zones I and II.

In the MONA experiments $[1,2,3,4,12] \cup$ was hardly detected in the outer layer of zone III, i.e. $a-\operatorname{Zr}(O)_{b}$ layer or only after very long reaction times [2]. Therefore, the diffusion of oxygen can be regarded as the rate determining step of the reaction in this layer (zone $/ 11$ ). In fact, almost the same activation energies of 232 and $229 \mathrm{~kJ} / \mathrm{mol}$ for the layer of $\mathrm{a}-\operatorname{Zr}(\mathrm{O})_{\mathrm{b}}$ and $\mathrm{a}-\operatorname{Zr}(\mathrm{O})_{c}$ are derived from the MONA data under oxidizing conditions. The layer $a-\operatorname{Zr}(O)_{C}$ is the inner one of the zone $1 V$ in which the diffusion of oxygen must be the rate determining step of the reaction. The zone I consists of the phases $a-\operatorname{Zr}(0)_{a}$ and $a(U, Z r)$ alloy preferentially along the grain boundaries. But, the $a-\operatorname{Zr}(O)_{a}$ matrix (grains) contains up to 
about 8 wt.\% uranium [2], which is homogeneously dissolved at temperature. The solubility of $U$ in $\mathrm{Zr}$ depends on the oxygen content of the $\mathrm{Zr}$ and, in accordance with the ternary U-Zr-O phase diagram, increases with increasing oxygen content. The activation energy for zone $l$ is estimated to be $310 \mathrm{~kJ} / \mathrm{mol}$ as described above. This value is much larger than that for the $a-\operatorname{Zr}(0)$ layer only. Consequently, not only the diffusion of oxygen but also the behavior of the $(U, Z r)$ alloy and the $U$ in the matrix should be taken into account in the calculations of $\mathrm{UO}_{2} /$ Zry interaction experiments.

\subsection{Conclusions}

The pyrometrically measured nominal test temperatures of the MONA $\left(\mathrm{UO}_{2} / \mathrm{Zry}\right.$ interaction) experiments were re-evaluated and corrected, and the previously determined reaction kinetics equations were revised by considering both the corrected actual test temperature and the corrected equivalent isothermal annealing time. The conclusions can be summarized as follows:

(1) In the isothermal $\mathrm{UO}_{2}$ /Zircaloy reaction experiments under oxidizing conditions, the test temperatures were underestimated by about 20 to $40^{\circ} \mathrm{C}$ in the temperature range between 1000 and $1400^{\circ} \mathrm{C}$.

(2) In the isothermal $\mathrm{UO}_{2}$ /Zircaloy reaction experiments in $\mathrm{Ar}$, the test temperatures were underestimated by about 10 to $80{ }^{\circ} \mathrm{C}$ in the temperature range between 1000 and $1200^{\circ} \mathrm{C}$, and overestimated by about 40 to $100^{\circ} \mathrm{C}$ in the range between 1400 and $1700^{\circ} \mathrm{C}$.

(3) The growth rates of the reaction zones measured in the isothermal $\mathrm{UO}_{2}$ /Zircaloy reaction experiments have been determined over the temperature range $900-1400$ and $1000-1600{ }^{\circ} \mathrm{C}$ for the tests under oxidizing conditions and in Ar, respectively.

(4) The comparisons of the activation energies estimated for the growth of reaction zones measured in the $\mathrm{UO}_{2} /$ zircaloy reaction experiments and those reported for oxygen diffusion in $a-\operatorname{Zr}(0)$ show significant differences. This suggests that the rate determining step of the reaction is not only the diffusion of oxygen but also the diffusion of uranium in the $a-\operatorname{Zr}(O)_{\text {a }}$ zone which contains in addition to oxygen some dissolved uranium. 


\section{Theoretical Results}

\subsection{Calculation of the Oxygen Diffusion Coefficients}

For the chemical interaction between $\mathrm{UO}_{2}$ and Zry a diffusion controlled process is assumed, whose rate determining step is oxygen diffusion [5,13], although it was shown in chapter 2.2 that this is not completely correct. The growth rates of the reaction zone thicknesses obey parabolic rate laws up to the moment when the cladding becomes oxygen saturated.

The oxygen concentration gradient across the cladding $\left(\mathrm{UO}_{2} \rightarrow\right.$ Zry $)$, resulting from the affinity of zirconium for oxygen, is the driving force for the reaction. The presence of metallic $\mathrm{Zr}$ in the $\mathrm{UO}_{2}$ matrix indicates that $\mathrm{Zr}$ diffusion and/or penetration also takes place but to a smaller extent than oxygen diffusion. $U$ diffusion also occurs to give origin to the $(U, \mathrm{Zr})$ alloy (rich in uranium) and the a$\mathrm{Zr}(\mathrm{O})_{a}$ phase which contains dissolved uranium and along the grain boundaries.

A general study of the problem has been performed by Olander [15] considering not only the diffusion of oxygen but also of $U$ and $Z r$. However, the large number of experimental and material properties data required to perform the calculations are presently not available for the temperatures of interest and therefore the results are restricted to the temperatures of $1500^{\circ} \mathrm{C}$ only.

A model is given in [5] which takes into account only oxygen diffusion. Starting from the experimental data published in [1,2]concerning the interface locations as functions of time and temperature, the mass balances at the four interfaces of the system are solved. The calculation code developed in [5] resulted in the determination of: a) the oxygen diffusion coefficients in the various phases, b) the oxygen concentrations at the interfaces in the temperature range 1000 to 1700 ${ }^{\circ} \mathrm{C}$ and $\mathrm{c}$ ) the oxygen concentration profile in the whole system as a function of position and time.

Early tungsten marker experiments reported in [13] indicates that the original $\mathrm{UO}_{2} / \mathrm{Zry}$ interface lies after interaction between the $(U, \mathrm{Zr})$ alloy and the $\mathrm{a}-\mathrm{Zr}(\mathrm{O})_{\mathrm{b}}$ layers. On that basis the equations presented in [5] were solved within the range of parabolic kinetics, i.e. under the assumption of an infinite system. More recent experiments with tungsten markers [1], however, have shown that the original 
$\mathrm{UO}_{2} / \mathrm{Zry}$ interface lies between the $\left[a-\operatorname{Zr}(0)_{a}+(U, \mathrm{Zr})\right]$ and $(U, Z r)$ layers. This means that the interface $\xi_{2}$ remains immobile as time progresses (figure 8 ).

The interface positions measured from the fuel-cladding interface reported in [1], plotted as functions of $\mathrm{V} t$ for different temperatures, give straight lines $\mathrm{du}$ ring the initial time period when the cladding may be considered to be infinite for the oxygen diffusion process. When oxygen saturation in the $\beta$-phase begins to occur the parabolic rate law is no more valid. The $a-\operatorname{Zr}(O)_{b} / \beta-Z r y$ interface movement suffers a certain acceleration, during a rather short period until when it reaches a stationary value. The other interfaces, one at a time, repeat the same procedure as it was shown in [16]. The slopes of the straight lines referred to above (figure 6) are temperature-dependent and the Arrhenius expressions are given on page $8(\mathrm{C})$.

It is natural to choose the origin of the abscissae at $\xi_{2}$ and to refer the other interface locations to that origin. Their parabolic rate laws may be simply calculated from:

$$
\begin{aligned}
& \xi_{1}=-\sqrt{K_{p}(I)} \sqrt{t} \\
& \xi_{3}=\left|\sqrt{K_{p}(I I)}-\sqrt{K_{p}(I)}\right| \sqrt{i} \\
& \xi_{4}=\mid \sqrt{K_{p}(I I)}-\sqrt{K_{p}(I)} \vee \bar{i}
\end{aligned}
$$

while $\xi_{2}=0$ at every time.

The oxygen concentration profiles at time $t=0$ and at time $=t$ are shown in figure 8 . They differ from those presented in [5] not only in the abscissae origin but also in the profile shape.

The parabolic rate laws for the interface positions may be summarized in the following expression:

$$
\xi_{i}=2 Y_{i} \sqrt{D_{5} t} \quad \text { with } i=1, \ldots, 4
$$

where $D_{5}$ is the oxygen diffusion coefficient in the $\beta$-phase and $y_{i}$ are dimensionless constants. 


\subsection{Oxygen Concentration at the Phase Boundaries}

In the equations, the oxygen concentrations at the various interfaces have to be given in $\mathrm{mg} / \mathrm{cm}^{3}$. The oxygen concentration in stoichiometric $\mathrm{UO}_{2}, \mathrm{C}_{1}$ (fig. 9), is determined with:

$$
C_{1}=\frac{x_{O} M_{O}}{x_{O} M_{O}+\left(1-x_{O}\right) M_{U}} \delta_{U O_{2}}
$$

where $M_{O}$ and $M_{U}$ are $O$ and $U$ atomic weights, $x_{O}$ is the atomic fraction of $0 x y$ gen (in this case $x_{O}=2 / 3$ ) and $\delta$ is the density. Theoretical calculations of the stoichiometric uranium dioxide density with natural isotopic content give 10960 $\mathrm{mg} / \mathrm{cm}^{3}$ at $25^{\circ} \mathrm{C}[17]$. Consideration of the temperature dependence of density due to thermal expansion originates differences of about 3 to $5 \%$ in $C_{1}$ for the temperatures considered here. Experimental errors are probably higher; for this reason thermal expansion effects are not taken into consideration. For $\mathrm{C}_{1}=$ $1298.6 \mathrm{mg} / \mathrm{cm}^{3}$ was obtained.

The reduction of uranium dioxide by $\mathrm{Zr}$ results in hypostoichiometric $\mathrm{UO}_{2}$. The oxygen concentration $C_{2}$ at the interface $\xi_{1}$ is rather difficult to determine as a function of temperature and will be estimated later on by a numerical method. The results are also shown in Figure 9.

In the second phase, $\left[a-\operatorname{Zr}(O)_{a}+(U, Z r)\right]$, metallographic observations indicate that the $(U, Z r)$ alloy, represents a small fraction of the phase (maximum $10 \%$ of the total volume [15]).. Its oxygen content is very low (less than 1 wt. \% 0$)[1,13]$. Moreover, the $U$ content of the $a-\operatorname{Zr}(O)_{a}$ grains is also very low. Consequently, it seems reasonable to assume that $C_{3}$ corresponds to oxygen saturated $a-\operatorname{Zr}(O)$. From the $\mathrm{Zr}$-O phase-diagram [18] we have fitted the following functions for the atomic fraction of oxygen:

$$
x_{O}=\mid \begin{array}{ll}
0.3 & \text { for } \mathrm{T}<1200^{\circ} \mathrm{C} \\
5.833 \cdot 10^{-8} T^{2}-1.333 \cdot 10^{-4} T+0.376 & \text { for } 1200^{\circ} \mathrm{C}<\mathrm{T}<1900^{\circ} \mathrm{C}
\end{array}
$$

The second branch of the function gives values slightly higher than 0.3 . 
In order to obtain $C_{3}$ in $\mathrm{mg} / \mathrm{cm}^{3}$ a calculation similar to that for $C_{1}$ (eq. (4) but with $\mathrm{M}_{2 r}$ instead of $\mathrm{MU}_{U}$ ) has to be performed. In the density determination the influence of the presence of oxygen on the lattice parameter must be considered. Beranger et al.[19] determined the volume of the elementary cell of $\mathrm{a}-\mathrm{Zr}(\mathrm{O})$ (containing 2 atoms of $\mathrm{Zr}$ ) at $850^{\circ} \mathrm{C}$, as a function of the atomic fraction of oxygen. The curve shows a plateau between 18 at. $\% 0$ and saturation at a value of $V\left(x_{0}, 850^{\circ} \mathrm{C}\right)=47.52 \AA 3$. Assuming that the curve shape remains unchanged in the temperature range of interest and that the oxygen content variation in the $\mathrm{a}-\mathrm{Zr}(\mathrm{O})_{a}$ domain is small enough as to make $x_{0}$ always fall within the plateau, then the only possible change in $V\left(x_{O}, T\right)$ will be due to thermal expansion. However, this effect is negligible.

The density is given by:

$$
\delta=\frac{x_{0} M_{O}+\left(1-x_{0}\right) M_{Z r}}{\left(1-x_{0}\right) A V\left(x_{0}, T^{T}\right) / 2}
$$

where $A$ is the Avogadro's number.

The final expression for $C_{3}$ is:

$$
c_{3}=\frac{x_{O}}{1-x_{O}} \frac{2 M_{O}}{A V\left(x_{O}, T\right)}
$$

With reference to $C_{4}, C_{6}$ and $C_{7}$ the same as for $C_{2}$ can be said. We expect $C_{4}$ and $C_{7}$ to be lower than $C_{3}$ as well as $C_{6}$ will be lower than $C_{5}$ and both of them lower than the AES detection limit. A tentative value of $35 \mathrm{mg} / \mathrm{cm}^{3}$ is assigned to $C_{5} . C_{3}$. $C_{4}$ and $C_{7}$ are plotted together in Figure 10 while $C_{5}$ and $C_{6}$, in Figure 11.

No $U$ has been found in the $a-Z r(O)_{b}$ - except for very long reaction times - nor in the $\beta$-Zry phases. The oxygen concentrations $C_{8}$ and $C_{9}$ at the $\alpha / \beta$-phase boundary were taken from the pseudo-binary diagram for Zircaloy-oxygen. The expressions published by Chung et al. [20] for the oxygen concentrations in weight per cent in the $\alpha$-and $\beta$-phase boundaries are:

$$
w_{8}=e^{-2.28}(T-1083)^{0.535}
$$




$$
w_{9}=e^{5.02-8220 / T}
$$

respectively, where $T$ is the absolute temperature. From these expressions $C_{8}$ and $\mathrm{C}_{9}$ are readily obtained.

$$
c_{i}=\frac{w_{i}}{100-w_{i}} \delta_{Z r} \quad \text { for } \mathrm{i}=8.9
$$

where $\delta_{Z r}=6489 \mathrm{mg} / \mathrm{cm}^{3}$ [21] represents the density of pure $\mathrm{Zr}$. $C_{8}$ and $C_{9}$ are represented in Fiqure 12.

At a sufficiently large distance from $\xi_{4}$ the oxygen concentration is that of the asreceived oxygen poor $Z$ ry. The value of $C_{10}$ is estimated to be about $8.5 \mathrm{mg} / \mathrm{cm}^{3}$.

\subsection{Oxygen Diffusion Coefficients in the Various Reaction Zones}

Because of the fact that no $U$ is present in phases $\alpha-\operatorname{Zr}(O)_{b}$ and $\beta$-Zry, their behavior with respect to oxygen diffusion is expected to be the same as during Zry oxidation by steam or oxygen. For the oxygen diffusion in $\beta-Z$ ry- 4 the following equation was used [22]:

$$
D_{5}=D_{\beta}=0.0263 \exp \left(-28200(\mathrm{cal} / \mathrm{mol}) / \mathrm{R}^{\prime} T^{\top}\right) \mathrm{cm}^{2} / \mathrm{s}
$$

Several investigators have reported the diffusivity of oxygen in a-Zry, [23], [24], [25] among others. Comparison is made below between our results for $D_{4}$ and these data.

The $(U, Z r)$ alloy, which can be liquid above $1150^{\circ} \mathrm{C}$ (depending on the $\mathrm{Zr}$ content [1]), is expected to behave like other liquids. In the Arrhenius expression of the self-diffusion coefficient of several liquid metals typical values are: frequency factor about $2.3 \cdot 10^{-3} \mathrm{~cm}^{2} / \mathrm{s}$ and activation energy (measured in $\mathrm{cal} / \mathrm{mol}$ ) about $9 T_{M}$ where $T_{M}$ is the melting point measured in $K$ [26]. This can give us a first rough approximation of the diffusivity of oxygen in the $(U, Z r)$ alloy above its melting point. Below this temperature little can be guessed about the diffusion 
behavior of the alloy, though it is commonly found that the Arrhenius lines for solid and liquid cross at the melting point.

In the second phase oxygen diffusion occurs partly through the a-Zr(O) grains and partly along the $(U, Z r)$ stringers. Its effective oxygen diffusion coefficient $\left(D_{2}\right)$ is expected to be intermediate between $D_{3}$ and $D_{4}$.

Experimental determinations of the chemical diffusion coefficient of oxygen in hypostoichiometric uranium dioxide indicate that for a given departure of stoichiometry its temperature dependence can be represented by Arrhenius lines with an activation energy of about $13 \mathrm{Kcal} / \mathrm{mol}(\simeq 54400 \mathrm{~J} / \mathrm{mol}$ ). It is also dependent on the $O / U$ ratio and its variation is stronger as the stoichiometric composition is approached [27]. For this reason the diffusion coefficient $D_{1}$ calculated in this paper has the meaning of an effective diffusion coefficient.

\subsection{Calculation Method}

The calculation consists of solving the equations system already solved in [5].

$$
\begin{aligned}
& Y_{1}=\frac{C_{1}-C_{2}}{C_{2}-C_{3}} \frac{e^{-\left(\gamma_{1} \phi_{1}\right)^{2}}}{\sqrt{n} \phi_{1}\left|1+\operatorname{erf}\left(Y_{1} \phi_{1}\right)\right|}-\frac{C_{3}-C_{4}}{C_{2}-C_{3}} \frac{e^{-\left(\gamma_{1} \phi_{2}\right)^{2}}}{\sqrt{n} \phi_{2}\left[\operatorname{erf}\left(Y_{2} \phi_{2}\right)-\operatorname{erf}\left(Y_{1} \phi_{2}\right) \mid\right.}
\end{aligned}
$$

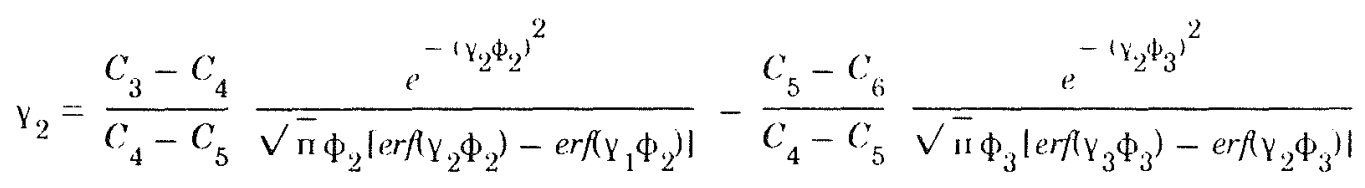

$$
\begin{aligned}
& \mathrm{Y}_{3}=\frac{C_{5}-C_{6}}{C_{6}-C_{7}} \frac{e^{-\left(\mathrm{V}_{3} \Phi_{3}\right)^{2}}}{\sqrt{\mathrm{n}} \Phi_{3}\left|\operatorname{erf}\left(\mathrm{Y}_{3} \Phi_{3}\right)-\operatorname{erf}\left(\mathrm{Y}_{2} \Phi_{3}\right)\right|}-\frac{C_{7}-C_{8}}{C_{6}-C_{7}} \frac{e^{-\left(\mathrm{V}_{3} \Phi_{4}\right)^{2}}}{\sqrt{\mathrm{II}} \phi_{4}\left|\operatorname{erf}\left(\mathrm{Y}_{4} \Phi_{4}\right)-\operatorname{erf}\left(\mathrm{Y}_{3} \phi_{4}\right)\right|} \\
& Y_{4}=\frac{C_{7}-C_{8}}{C_{8}-C_{9}} \frac{e^{-\left(\gamma_{4} \phi_{4}\right)^{2}}}{\sqrt{\pi} \Phi_{4} \operatorname{lerf}\left(\gamma_{4} \Phi_{4}\right)-\operatorname{erf}\left(Y_{3} \Phi_{4}\right) !}-\frac{C_{9}-C_{10}}{C_{8}-C_{9}} \frac{e^{-\gamma_{4}^{2}}}{\sqrt{n} \operatorname{erfcY_{4}}}
\end{aligned}
$$




$$
\begin{aligned}
& \text { where } \Phi_{i}=\sqrt{D_{5} / D_{i}} \\
& \text { and } \quad Y_{i}=\xi_{i} / 2 \sqrt{D_{5} t} \text { with } i=1, \ldots, 4
\end{aligned}
$$

The only but important difference here is that the proportionality constant y2 (instead of $\mathrm{y}_{3}$ ) is zero. The growth rate constants for the different zones are given as data and the diffusion coefficients are calculated. The last equation (15) is solved for $D_{4}$. This value is entered in (14) and $D_{3}$ is found and so on until $D_{1}$ is determined with (12).

The interface concentrations must be previously estimated in order to find a solution for the equations system. This causes the major calculation difficulties. When the layer growth rate constants calculated as Arrhenius lines (page 8) are put in the equations system, satisfactory results are obtained for the diffusion coefficient $D_{1}, \ldots, D_{4}$ in the lower temperature range if convenient values for $C_{2}$, $C_{4}, C_{6}$ and $C_{7}$ are found. Unfortunately, the same is not true at the higher temperatures (above about $1450^{\circ} \mathrm{C}$ ) where no solution can be found for $D_{1}$ (the last unknown in the calculation sequence) although a wide range of values for $C_{2}, C_{4}, C_{6}$ and $C_{7}$ is applied. For this reason it was attempted to look for solutions employing the experimental set of values of the kinetic constants for each temperature rather than the expression referred to above. But even in this case no high temperature solutions could be found. Then, the hypothesis was made that the high temperature correction, which is based on a low temperature extrapolation, could not be good enough for the model. Moreover, it was noted that small variations in some parameters, either temperature or thicknesses of reaction layers, produced important changes in the results. So, we turned back to the experimental determinations and tried to guess what temperature values yielded reasonable solutions for the diffusion coefficients, i.e. what temperature values produced linear extrapolations in the Arrhenius plots of the diffusion coefficients. The data set employed at the three higher temperatures is:

For a given set of concentration values and a given temperature, the code calculates the diffusion coefficients $D_{1}, D_{2}, D_{3}$ and $D_{4}$, asking for new values of $C_{2}, C_{4}$, $C_{6}, C_{7}$ and $T$ if the extrapolations are not satisfactory. 


$\begin{array}{llll}T\left({ }^{\circ} \mathrm{C}\right) & K_{p}(1)\left(\mathrm{cm}^{2} / \mathrm{s}\right) & K_{p}(11)\left(\mathrm{cm}^{2} / \mathrm{s}\right) & K_{p}(I I I)\left(\mathrm{cm}^{2} / \mathrm{s}\right) \\ 1520 & 5.36 \cdot 10^{-7} & 1.04 \cdot 10-6 & 4.28 \cdot 10-6 \\ 1640 & 1.21 \cdot 10^{-6} & 2.77 \cdot 10-6 & 7.85 \cdot 10-6 \\ 1675 & 2.06 \cdot 10^{-6} & 7.17 \cdot 10-6 & 1.92 \cdot 10-5\end{array}$

\subsection{Results and Discussion}

Once adequate solutions were found, functions were fitted for the concentrations. The expressions obtained, represented in figs. 9, 10 and 11, are:

$$
\begin{array}{ll}
C_{2}=\mid \begin{array}{ll}
\left.1231.1 \exp \mid 5.036 \cdot 10^{-8}(T-1604.41)^{2}\right) & \text { for } 1273 \mathrm{~K}<\mathrm{T}<1793 \mathrm{~K} \\
1277.5+8.8545 \cdot 10^{-3} T & \text { for } 1793 \mathrm{~K}<\mathrm{T}<2023 \mathrm{~K}
\end{array} \\
C_{4}=\mid \begin{array}{ll}
455.97+1.3725 \cdot 10^{-2} T & \text { for } 1273 \mathrm{~K}<\mathrm{T}<1523 \mathrm{~K} \\
478.28-8.7964 \cdot 10^{-4} T & \text { for } 1523 \mathrm{~K}<\mathrm{T}<2023 \mathrm{~K}
\end{array} \\
C_{6}=\mid \begin{array}{ll}
44.11-5.9303 \cdot 10^{-3} T \\
-771.31+0.901181 T-2.5266 \cdot 10^{-4} T^{2}
\end{array} & \text { for } 1551 \mathrm{~K}<\mathrm{T}<1793 \mathrm{~K} \\
C_{7}=-2956.1+466.84 \ln (T-273) & \text { for } 1793 \mathrm{~K}<\mathrm{T}<2023 \mathrm{~K}
\end{array}
$$

where concentrations are given in $\mathrm{mg} / \mathrm{cm}^{3}$ and temperatures in $\mathrm{K}$.

These functions were introduced in the code and the effective oxygen diffusion coefficients for the various reaction zones were again calculated. Their values and the least squares Arrhenius lines are shown in Figure 13. They are:

$$
\begin{aligned}
& D_{1}=3.4845 \cdot 10^{-3} \exp \left(-57996 / R^{\prime} T\right) \quad \text { for } 1273 \mathrm{~K}<\mathrm{T}<2023 \mathrm{~K}
\end{aligned}
$$

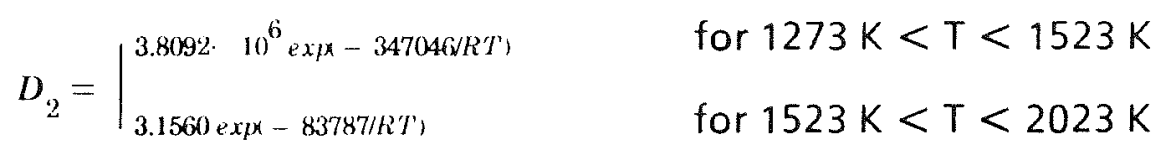




$$
\begin{aligned}
& D_{3}=\mid \begin{array}{ll}
\left.6.4118 \cdot 10^{6} \operatorname{expl}-332301 / R T\right) & \text { for } 1273 \mathrm{~K}<\mathrm{T}<1523 \mathrm{~K} \\
\left.2.0852 \cdot 10^{-3} \exp _{\exp }-53755 / R T\right) & \text { for } 1523 \mathrm{~K}<\mathrm{T}<2023 \mathrm{~K}
\end{array} \\
& D_{4}=0.63115 \exp (-191673 / R T) \quad \text { for } 1273 \mathrm{~K}<\mathrm{T}<2023 \mathrm{~K}
\end{aligned}
$$

where $T$ is given in $K$, the activation energies in $\mathrm{J} / \mathrm{mol}$ and the diffusion coefficients in $\mathrm{cm}^{2} / \mathrm{s}$. These expressions for the oxygen diffusivity in the various phases. agree quite well with the expected values. The solid-to-liquid phase change of the $(U, Z r)$ alloy must be reflected in the diffusion coefficients $D_{3}$ and $D_{2}$ the melting point has been determined to be about $1250^{\circ} \mathrm{C}$ [1]. A little difference appears in our results and we obtain a knee in $D_{3}$ and $D_{2}$ around $1250^{\circ} \mathrm{C}$.

In order to check the correctness of our results, the reverse problem was solved, i.e. with the functions $16-20$, eqs. 12 - 15 were solved for $\mathrm{Yi}(i=1, \ldots, 4)$. Then the layer thicknesses measured from the interface $\xi_{1}$ were determined from:

$$
\begin{aligned}
& K^{\prime}(I)=4 D_{5}\left(Y_{2}-Y_{1}\right)^{2} \\
& K^{\prime}(I I)=4 D_{5}\left(Y_{3}-Y_{1}\right)^{2} \\
& K^{\prime}\left(\text { III) }=4 D_{5}\left(Y_{4}-Y_{1}\right)^{2}\right.
\end{aligned}
$$

The calculation was performed every $25^{\circ} \mathrm{C}$ between 1000 and $1750^{\circ} \mathrm{C}$ and least squares Arrhenius lines were determined for the kinetic constants. Both are shown in Figure 14.

$$
\begin{aligned}
& K^{\prime}(I)= \begin{cases}1.3628 \cdot 10^{4} \exp \left(-34\left(0744 / K^{\prime} T\right)\right. & \text { for } 1273 \mathrm{~K}<\mathrm{T}<1523 \mathrm{~K} \\
1.748(0) \exp x-22366\left(69 / K^{T} T\right) & \text { for } 1523 \mathrm{~K}<\mathrm{T}<2023 \mathrm{~K}\end{cases} \\
& K^{\prime}(I I)= \begin{cases}\left.1.4112 \cdot 10^{5} \exp -362(17) / R^{\prime}\right) & \text { for } 1273 \mathrm{~K}<\mathrm{T}<1523 \mathrm{~K} \\
\left.47.490 \exp x-259172 / R^{\prime} T^{\prime}\right) & \text { for } 1523 \mathrm{~K}<\mathrm{T}<2023 \mathrm{~K}\end{cases} \\
& K^{\prime}(I I I)=6.3614 \exp \left(-209818 / R^{\prime} T\right) \quad \text { for } 1273 K<\mathrm{T}<2023 \mathrm{~K}
\end{aligned}
$$

The calculated results are in reasonalby good agreement with the experimental data especially in the low temperature range (Figure 15). But, for the higher temperatures the extrapolation of the model does not match so well with the 
experimental points. Equations 21 represent the best compromise between the experimental data and the solution of the model.

\subsection{Conclusions}

(1) Using the new Arrhenius equations, describing the growth rate of the various $\mathrm{UO}_{2}$ /Zircaloy interaction layers, for the determination of the effective oxygen diffusion coefficients good solutions are obtained for temperatures below $1300^{\circ} \mathrm{C}$. At higher temperatures the agreement between the experimental results and the model predictions is not as good.

(2) The solid-to-liquid phase change of the $(U, \mathrm{Zr})$ alloy is reflected, as it was expected, in the oxygen diffusion coefficient $D_{2}$ and $D_{3}$ which show a change in slope around $1250^{\circ} \mathrm{C}$. This temperature corresponds to the experimentally determined melting point of the $(U, Z r)$ alloy, which depends on the Zr content [1].

(3) The new Arrhenius equations for the oxygen diffusion coefficients together with the functions fitted for the oxygen concentration at the phase boundaries allow the calculation of the $\mathrm{UO}_{2}$ /Zircaloy interaction also for temperature transient experiments.

\section{Acknowledgements}

We would like to thank Prof. Dr. W. Dienst and Dr. R.R. Hobbins (EG $+G)$ Idaho. USA, for their thorough review of the manuscript.

The work was sponsored by "Projekt Nukleare Sicherheit" (PNS/KfK). 


\section{References}

[1] P. Hofmann, D.K. Kerwin-Peck, $\mathrm{UO}_{2}$ /Zircaloy-4 Chemical Interactions and Reaction Kinetics from 1000 to $1700{ }^{\circ} \mathrm{C}$ under Isothermal Conditions (Final Report), KfK 3552, November 1983.

[2] P. Hofmann, D.K. Kerwin-Peck,

$\mathrm{UO}_{2}$ /Zircaloy-4 Chemical Interactions and Reaction Kinetics from 1000 to $1700{ }^{\circ} \mathrm{C}$ under Isothermal and Transient Temperature Conditions, J. Nucl. Mat., 124, 1984, pp. $80-105$.

[3] P. Hofmann, H.J. Neitzel,

"External and Internal Reaction of Zircaloy Tubing with Oxygen and $\mathrm{UO}_{2}$ and its Modeling". Fifth International Meeting on "Thermal Nuclear Reactor Safety", September 9 - 13, 1984, Karlsruhe, FRG. Proc. Vol. 2, pp. $1015-1025$

[4] P. Hofmann et al.,

"Mechanisches und chemisches Verhalten von Zircaloy-4-Hüllrohren und $\mathrm{UO}_{2}$-Brennstoff bei hohen Temperaturen", PNS-Jahresbericht 1983, KfK 3450 (1984),pp. 4200/126- 145

[5] A. Denis, E.A. Garcia,

"Model to Describe the Interaction Between $\mathrm{UO}_{2}$ and Zircaloy in the Temperature Range 1000 to $1700^{\circ} \mathrm{C}$ ", J. Nucl. Mater., 116, 1983, pp. 44 54.

[6] A.W. Cronenberg, M.S. El-Genk,

"An Assessment of Oxygen Diffusion During UO $\mathrm{U}_{2} /$ Zry Interaction", J. Nucl. Mater., 78, 1978, pp. $390-407$.

[7] H. Uetsuka, P. Hofmann, Reaction Kinetics of Zircaloy-4 in a $25 \% \mathrm{O}_{2} / 75 \%$ Ar Gas Mixture from 900 to $1500{ }^{\circ} \mathrm{C}$ under Isothermal Conditions, KfK 3917, 1985.

[8] P. Hofmann et al., unpublished data.

[9] J.V. Cathcart, R.E. Pawel, R.A. Mckee, R.E. Druschel, G.J. Yurek, J.J. Campbell, S.H. Jury,

Zirconium Metal-Water Oxidation Kinectics IV. Reaction Rate Studies, ORNL/NUREG-17, August 1977.

[10] S. Leistikow, G. Schanz,

"High Temperature Oxidation of Zircaloy-4 Cladding Tubes in Steam (600

$\left.-1600^{\circ} \mathrm{C}\right)$ ", 9th International Congress on Metallic Corrosion, June 3 - 7. 1984, Toronto, Canada.

[11] V.F. Urbanic, T.R. Heidrick,

"High-Temperature Oxidation of Zircaloy-2 and Zircaloy-4 in Steam", J. Nucl. Mater., 75, 1978, pp. $251-261$. 
[12] P. Hofmann, H.J. Neitzel,

"Experimental and Theoretical Results of Cladding Oxidation under Severe Fuel Damage Conditions" "Seventh International Conference on Zirconium in the Nuclear Ind ustry, 24 - 27 June 1985, Strasbourg, France.

[13] P. Hofmann, C. Politis,

"The Kinetics of the UO2-Zircaloy Reactions at High Temperatures", J. Nucl. Mater., 87, (1979) pp. $375-397$.

[14] B.D. Johnston,

"The Zircaloy-UO 2 Reaction", SRD-R-294 (1984).

[15] D.R. Olander,

"The UO 2 -Zircaloy Chemical Interaction" J. Nucl. Mater., 115, (1983) 271.

[16] A. Denis and E.A. Garcia.

"Simulation of the Interaction Between Uranium Dioxide and Zircaloy. Fifth International Meeting on Thermal Reactor Safety, Karlsruhe, Germany, Sept. 1984, p. 1026.

[17] J. Belle,

Uranium Dioxide: Properties and Nuclear Applications (United States Atomic Energy Commision, Washington, 1961).

[18] R.P. Elliot,

Constitution of Binary Alloys, First Supplement. McGraw-Hill, 1965.

[19] P. Boisssot and G. Béranger,

"Variations des parametres cristallins de la solution solide a-ZirconiumOxygène en fonction de la teneur en oxygène". C.R. Acad. Sc. Paris, (1969) t. 269, p. 587

[20] H.M. Chung and T.F. Kassner,

"Pseudobinary Zircaloy-Oxygen Phase Diagram". J. Nucl. Mater. 84 (1979) p. 327.

[21] Metals Handbook, Desk Editions, Amer. Soc. for Metals (1984).

[22] R.A. Perkins,

"Oxygen diffusion in $\beta$-Zircaloy". J. Nucl. Mater. 68 (1977) pp. 148 - 160.

[23] R.E. Pawel,

"Oxygen diffusion in the Oxide and Alpha Phases during Reaction of Zircaloy-4 with Steam from $1000^{\circ}$ to $1500^{\circ} \mathrm{C}^{\prime \prime}$. J. Electroch. Soc., Vol. 126, N7,(1979) p. 1111-1118.

[24] D. David, G. Amsel, P. Boissot and G. Béranger,

"A Study of the Diffusion of Oxygen in Alpha-Zirconium by Means of Nuclear Microanalysis". J. Electroch. Soc., Vol. 122, N 3 (1975) p. 388-396.

[25] I.G. Ritchie and A. Atrens,

"Diffusion of Oxygen in Alpha-Zirconium". J. Nucl. Mater. 67 (1977) p. 254.

[26] N.A. Gjostein,

"Short Circuit Diffusion". Diffusion. Papers presented at a Seminar of the American Soc. for Metals, 14-15 Oct. 1972, Boston. 
[27] A.S. Bayoglu and R. Lorenzelli,

"Oxygen diffusion in fcc fluorite type nonstoichiometric nuclear oxide $\mathrm{MO}_{2 \pm x}$ ", Second International Conference on Transport in Non-Stochiometric Compounds 81984); Solid State Ionics 12(1984) p. 53-66. 


\section{List of Tables}

Table 1: Equivalent isothermal annealing times estimated for the heat-up $(10 \mathrm{~K} / \mathrm{s})$ and cool-down $(5 \mathrm{~K} / \mathrm{s})$ periods of the temperature transient.

Table 2: Data of the isothermal $\mathrm{UO}_{2}$ Zircaloy interaction experiments under oxidizing conditions and the estimated temperatures.

Table 3: Comparison of the measured reaction zone thicknesses in the MONA temperature transient tests with the values calculated on the basis of the kinetics equations and estimated equivalent isothermal annealing times.

Table 4: Parabolic rate law constants for zones $1-\mathrm{V}$ in the $\mathrm{UO}_{2}$ /Zircaloy interaction experiments under oxidizing conditions (calculated by the least square method).

Table 5: Temperature dependence of the parabolic rate constants for the reaction zones $1-V$ in the $\mathrm{UO}_{2}$ /Zircaloy reaction experiments under oxidizing conditions.

Table 6: $\mathrm{UO}_{2}$ /Zircaloy reaction experiments in $\mathrm{Ar}$ and estimations of the reaction temperatures.

Table 7: Average of estimated temperatures and corrected temperatures for the $\mathrm{UO}_{2}$ /Zircaloy reaction experiments in Ar.

Table 8: Regression constants calculated by the method of least squares for the $\mathrm{UO}_{2}$ /Zircaloy reaction kinetics data in $\mathrm{Ar}$. 


\section{List of Figures}

Fig. 1: Schematic illustration of the sequence of $\mathrm{UO}_{2} / \mathrm{Zry}$ reaction layers and the definition of the various reaction zones.

Fig. 2: Sequence of the kinetics data correction for the $\mathrm{UO}_{2}$ /Zircaloy interaction experiments.

Fig. 3: Schematic illustration of the typical heat-up and cool-down rates in the $\mathrm{UO}_{2}$ /Zircaloy interaction experiments and its correction by an equivalent isothermal annealing time.

Fiq.4: Arrhenius plot of the parabolic rate constants for the growth of the reaction zones $I$ - $V$ in the $U_{2}$ /Zircaloy reaction experiments under oxidizing conditions.

Fig. 5: Correlation between nominal test temperatures in the $\mathrm{UO}_{2} / \mathrm{Zry}$ reaction experiments in Ar and corrected temperatures.

Fig. 6: Arrhenius plot of the parabolic rate constants for the growth of zones I, II and III in the $\mathrm{UO}_{2}$ /Zircaloy interaction experiments in $\mathrm{Ar}$ (corrected data).

Fig. 7: Comparison of the previously determined and the corrected parabolic rate constants for the growth of zones 1,11 and 111 in the $\mathrm{UO}_{2} /$ Zircaloy interaction experiments in Ar.

Fig. 8: At $t=0, \mathrm{UO}_{2}$ and Zircaloy are brought into solid contact (upper scheme). The oxygen concentration profile is indicated below by the bold line. After some annealing time $(t>0)$ several phases have formed (lower scheme) separated by moving interfaces $\xi_{1}, \xi_{3}$ and $\xi_{4}$. At every instant $\xi_{2}=0$; this is chosen as the origin of the coordinate system.

Fig. 9: Interface concentrations $C_{1}$ and $C_{2} . C_{1}$ is temperature independent and equal to $1298.6 \mathrm{mg} / \mathrm{cm}^{3}$ (eq. 4). The points represent the values of $\mathrm{C}_{2}$ employed in the calculations and the curve represents the function (16) which fits best to the points.

Fig. 10: Temperature dependence of the interface concentrations $C_{3}, C_{4}$ and $C_{7} . C_{3}$ is given by (7). The points represent the values of $C_{4}$ and $C_{7}$ used in the calculations and the curves represent the functions (17) and (19) which fit best to the points.

Fig. 11: Interface concentrations $C_{5}$ and $C_{6} . C_{5}$ is chosen temperature independent and equal to $35 \mathrm{mg} / \mathrm{cm}^{3}$. The points represent the values of $C_{6}$ used in the calculations and the curve represents the function (18) which fits best to the points.

Fig. 12: Temperature dependence of the interface concentrations $C_{8}$ and $C_{9}$ given in (10).

Fig. 13: Diffusion coefficients of oxygen in the five phases of the system. The points represent the solutions of eqs. $12-15$ when eqs. $4,7,10,16-19$ are entered as data. The lines represent $D_{5}$ (eq. 11) and the Arrhenius functions (20) which fit best to the points. 
Fig. 14: Kinetic constants $K^{\prime}(1), K^{\prime}(I I)$ and $K^{\prime}(I I I)$ for the growth of zone I, II and III, respectively. The points represent the solutions of eqs. $12-15$ taking the concentrations from eqs. $4,7,10,16-19$ and the diffusion coefficients from eq. (20). The lines represent the Arrhenius functions (21) which fit best to the points.

Fig. 15: The points represent the experimentally determined kinetic constants $K_{p}$ (I), $K_{p}$ (II) and $K_{p}$ (III) for the growth of zones I, II and III, respectively. The lines representing eq. (21) are superimposed for comparison. 
Table 1: Equivalent isothermal annealing times estimated for the heatup $(10 \mathrm{~K} / \mathrm{s})$ and cooldown $(5 \mathrm{~K} / \mathrm{s})$ periods of the temperature transient.

\begin{tabular}{|c|c|c|c|}
\hline \multirow{2}{*}{$\begin{array}{l}\text { Maximum } \\
\text { Nominal } \\
\text { Temperature of } \\
\text { the transient } \\
\left({ }^{\circ} \mathrm{C}\right)\end{array}$} & \multicolumn{3}{|c|}{ Estimated Equivalent Annealing Time } \\
\hline & $\begin{array}{c}\text { for Heatup } \\
\text { (s) }\end{array}$ & $\begin{array}{l}\text { for Cooldown } \\
\text { (s) }\end{array}$ & $\begin{array}{c}\text { for Overall } \\
\text { Transient } \\
\text { (s) }\end{array}$ \\
\hline 1000 & 8.0 & 12.9 & 20.9 \\
\hline 1100 & 9.1 & 13.3 & 22.4 \\
\hline 1200 & 10.2 & 16.7 & 26.9 \\
\hline 1300 & 11.4 & 19.4 & 30.8 \\
\hline 1400 & 12.6 & 22.1 & 34.7 \\
\hline 1500 & 14.0 & 24.9 & 38.9 \\
\hline 1600 & 15.4 & 27.7 & 43.1 \\
\hline 1700 & 16.8 & 30.6 & 47.4 \\
\hline
\end{tabular}


Table 2: Data of the $\mathrm{UO}_{2} /$ Zircaloy interaction experiments under oxidizing conditions and the estimated temperatures.

\begin{tabular}{|c|c|c|c|c|c|}
\hline \multicolumn{2}{|c|}{$\begin{array}{l}\text { Nominal Test } \\
\text { Temperature and } \\
\text { Annealing Time }\end{array}$} & \multirow{2}{*}{$\begin{array}{l}\text { Estimated } \\
\text { Equivalent } \\
\text { Isothermal } \\
\text { Annealing } \\
\text { Time } \\
\text { (s) }\end{array}$} & \multirow{2}{*}{$\begin{array}{c}\text { Average } \\
\text { Oxide Layer } \\
\text { Thickness } \\
{[12]} \\
(\mu \mathrm{m})\end{array}$} & \multirow{2}{*}{$\begin{array}{c}\text { Estimated } \\
\text { Temperature } \\
\left({ }^{\circ} \mathrm{C}\right)\end{array}$} & \multirow{2}{*}{$\begin{array}{c}\text { Average } \\
\text { Temperature } \\
\left({ }^{\circ} \mathrm{C}\right)\end{array}$} \\
\hline$\left({ }^{\circ} \mathrm{C}\right)$ & $(\min )$ & & & & \\
\hline \multirow[t]{2}{*}{900} & 10 & 678 & 13.4 & 901 & 899 \\
\hline & 30 & 1878 & 21.4 & 897 & \\
\hline \multirow[t]{3}{*}{1020} & 6 & 261 & 27.6 & 1039 & 1046 \\
\hline & 10 & 681 & 47.5 & 1047 & \\
\hline & 30 & 1881 & 81.7 & 1051 & \\
\hline \multirow[t]{3}{*}{1100} & 6 & 262 & 48.0 & 1137 & 1140 \\
\hline & 10 & 682 & 78.5 & 1141 & \\
\hline & 30 & 1882 & 130.3 & 1141 & \\
\hline \multirow[t]{2}{*}{1200} & 6 & 267 & 68.6 & 1243 & 1244 \\
\hline & 10 & 687 & 110.7 & 1244 & \\
\hline \multirow[t]{2}{*}{1300} & 6 & 271 & 89.8 & 1316 & 1318 \\
\hline & 10 & 691 & 145.2 & 1319 & \\
\hline \multirow[t]{2}{*}{1400} & 6 & 275 & 136.6 & 1412 & 1416 \\
\hline & 10 & 695 & 227.5 & 1420 & \\
\hline
\end{tabular}

* The estimated equivalent isothermal annealing time is composed of the nominal annealing time plus the equivalent isothermal annealing time estimated for the heatup and cooldown periods (table 1) plus 60 seconds for which the specimen was held at temperature to allow the cladding and fuel to reach thermal equilibrium before the external pressure was applied $[1,2$; figure 2]. For this reason, the time for the $\mathrm{O}_{2} / \mathrm{Zry}$ interactions is always larger than that for the $\mathrm{UO}_{2} /$ Zry interactions. 
Table 3: Comparison of the measured reaction zone thicknesses in the MONA temperature transient tests* with the values calculated on the basis of the kinetics equations (Table 5) and estimated equivalent isothermal annealing times (Table 2).

\begin{tabular}{|c|c|c|c|c|c|c|c|c|c|c|}
\hline \multirow{3}{*}{$\begin{array}{l}\text { Maximum } \\
\text { Nominal } \\
\text { Temperature } \\
\text { of the } \\
\text { Transient } \\
\left({ }^{\circ} \mathrm{C}\right)\end{array}$} & \multicolumn{10}{|c|}{ Thickness of each reaction zone $(\mu \mathrm{m})$} \\
\hline & \multicolumn{2}{|c|}{ I } & \multicolumn{2}{|c|}{ II } & \multicolumn{2}{|c|}{ III } & \multicolumn{2}{|c|}{ IV } & \multicolumn{2}{|c|}{$\mathbf{V}$} \\
\hline & m.t.** & C.V. ${ }^{* *}$ & m.t. & C.V. & m.t. & c.v. & m.t. & c.v. & m.t. & c.v. \\
\hline 1100 & 3 & 1.7 & 5 & 2.4 & 10 & 8.5 & 47 & 34.8 & 26 & 12.1 \\
\hline 1200 & 7 & 4.4 & 10 & 5.9 & 25 & 18.9 & 71 & 64.7 & 38 & 20.4 \\
\hline 1300 & 13 & 10.2 & 17 & 12.9 & 49 & 37.1 & 111 & 109.9 & 54 & 31.9 \\
\hline 1400 & 22 & 21.1 & 28 & 25.5 & 70 & 67.3 & 172 & 175.0 & 77 & 47.2 \\
\hline 1500 & 27 & 40.4 & 38 & 46.9 & 80 & 114.3 & & & & \\
\hline 1600 & 55 & 72.2 & 91 & 80.8 & 177 & 183.4 & & & & \\
\hline 1700 & 84 & 121.8 & 150 & 131.9 & 258 & 281.1 & & & & \\
\hline
\end{tabular}

*: heat-up rate $=10 \mathrm{~K} / \mathrm{s}$, cool-down rate $=5 \mathrm{~K} / \mathrm{s}$.

$\star \star:$ m.t. $=$ measured thickness, c.v. = calculated values 
Table 4: Parabolic rate law constants for zones $\mathrm{I}-\mathrm{V}$ in the $\mathrm{UO}_{2}$ /Zircaloy interaction experiments under oxidizing conditions (calculated by the least square method) for the estimated average temperatures listed in table 2.

\begin{tabular}{|c|c|c|c|c|c|}
\hline $\begin{array}{c}\text { Temp. } \\
\left({ }^{\circ} \mathrm{C}\right)\end{array}$ & I & II & III & IV & $\mathbf{V}$ \\
\hline 899 & $\begin{array}{l}6.51 \cdot 10^{-11} \\
100 \sim 120 \mathrm{~min}\end{array}$ & - & $\begin{array}{l}1.69 \cdot 10-9 \\
30 \sim 120 \mathrm{~min}\end{array}$ & $\begin{array}{l}8.30 \cdot 10^{-9} \\
31 \sim 121 \mathrm{~min}\end{array}$ & $\begin{array}{l}2.39 \cdot 10^{-9} \\
11 \sim 31 \mathrm{~min}\end{array}$ \\
\hline 1046 & $\begin{array}{l}1.61 \cdot 10^{-9} \\
10 \sim 150 \mathrm{~min}\end{array}$ & $\begin{array}{l}3.66 \cdot 10-9 \\
10 \sim 150 \mathrm{~min}\end{array}$ & $\begin{array}{l}1.95 \cdot 10-8 \\
30 \sim 150 \mathrm{~min}\end{array}$ & $\begin{array}{l}1.01 \cdot 10^{-7} \\
4 \sim 151 \mathrm{~min}\end{array}$ & $\begin{array}{l}3.85 \cdot 10-8 \\
4 \sim 151 \mathrm{~min}\end{array}$ \\
\hline 1140 & $\begin{array}{l}4.31 \cdot 10 \cdot 9 \\
3 \sim 150 \mathrm{~min}\end{array}$ & $\begin{array}{l}8.62 \cdot 10-9 \\
3 \sim 150 \mathrm{~min}\end{array}$ & $\begin{array}{l}9.82 \cdot 10-8 \\
3 \sim 30 \mathrm{~min}\end{array}$ & $\begin{array}{l}3.20 \cdot 10^{-7} \\
4 \sim 31 \mathrm{~min}\end{array}$ & $\begin{array}{l}9.45 \cdot 10-8 \\
4 \sim 61 \mathrm{~min}\end{array}$ \\
\hline 1244 & $\begin{array}{l}2.24 \cdot 10^{-8} \\
3 \sim 60 \mathrm{~min}\end{array}$ & $\begin{array}{l}3.64 \cdot 10-8 \\
3 \sim 60 \mathrm{~min}\end{array}$ & $\begin{array}{l}4.55 \cdot 10^{-7} \\
3 \sim 30 \mathrm{~min}\end{array}$ & $\begin{array}{l}1.15 \cdot 10^{-6} \\
4 \sim 31 \mathrm{~min}\end{array}$ & $\begin{array}{l}2.23 \cdot 10-7 \\
4 \sim 61 \mathrm{~min}\end{array}$ \\
\hline 1318 & $\begin{array}{l}7.33 \cdot 10-8 \\
3 \sim 30 \mathrm{~min}\end{array}$ & $\begin{array}{l}1.11 \cdot 10^{-7} \\
3 \sim 30 \mathrm{~min}\end{array}$ & $\begin{array}{l}1.11 \cdot 10-6 \\
3 \sim 10 \mathrm{~min}\end{array}$ & $\begin{array}{l}2.00 \cdot 10-6 \\
3 \sim 10 \mathrm{~min}\end{array}$ & $\begin{array}{l}3.53 \cdot 10^{-7} \\
4 \sim 31 \mathrm{~min}\end{array}$ \\
\hline 1416 & $\begin{array}{l}2.39 \cdot 10-7 \\
3 \sim 10 \mathrm{~min}\end{array}$ & $\begin{array}{l}3.63 \cdot 10-7 \\
3 \sim 10 \mathrm{~min}\end{array}$ & $\begin{array}{l}1.76 \cdot 10-6 \\
3 \sim 10 \mathrm{~min}\end{array}$ & $\begin{array}{c}4.20 \cdot 10^{-6} \\
4 \sim 11 \mathrm{~min}\end{array}$ & $\begin{array}{l}7.30 \cdot 10^{-7} \\
4 \sim 11 \mathrm{~min}\end{array}$ \\
\hline
\end{tabular}

*: The temperature is estimated from the thickness of the $\mathrm{ZrO}_{2}$ layer using the equivalent isothermal annealing time (see table 2). 
Table 5: Temperature dependence of the parabolic rate constants for the reaction zones I- $V$ in the $\mathrm{UO}_{2}$ /Zircaloy reaction experiments under oxidizing conditions.

\begin{tabular}{|c|l|c|}
\hline Zone & \multicolumn{1}{|c|}{ Arrhenius equation } & Temperature Range $\left({ }^{\circ} \mathrm{C}\right)$ \\
\hline I & $\mathrm{K}_{p}(\mathrm{I})=245.3 \exp (-290,988 / \mathrm{RT})$ & $1100 \sim 1400$ \\
\hline II & $\mathrm{K}_{\mathrm{p}}(\mathrm{II})=83.1 \exp (-270,613 / \mathrm{RT})$ & $1100 \sim 1400$ \\
\hline III & $\mathrm{K}_{p}(\mathrm{III})=35.2 \exp (-231,692 / \mathrm{RT})$ & $900 \sim 1400$ \\
\hline IV & $\mathrm{K}_{p}(\mathrm{IV})=3.13 \exp (-188,742 / \mathrm{RT})$ & $1000 \sim 1400$ \\
\hline V & $\mathrm{K}_{\mathrm{p}}(\mathrm{V})=2.26 \cdot 10-6 \exp (-145,636 / \mathrm{RT})$ & $1000 \sim 1400$ \\
\hline
\end{tabular}


Table 6: $\mathrm{UO}_{2} /$ Zircaloy reaction experiments in Ar and estimations of the reaction temperatures.

\begin{tabular}{|c|c|c|c|c|c|c|c|}
\hline \multirow{2}{*}{$\begin{array}{l}\text { Nominal } \\
\text { Temp. } \\
\left({ }^{\circ} \mathrm{C}\right)\end{array}$} & \multirow{2}{*}{$\begin{array}{c}\text { Annealing } \\
\text { Time } \\
\text { (min) }\end{array}$} & \multicolumn{3}{|c|}{ Layer thickness ( $\mu \mathrm{m})$} & \multicolumn{3}{|c|}{ Estimated Temperature $\left({ }^{\circ} \mathrm{C}\right)$} \\
\hline & & 1 & $\|$ & III & 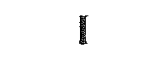 & II & III \\
\hline \multirow[t]{4}{*}{1000} & 10 & 7 & 11 & 52 & - & - & 1087 \\
\hline & 20 & 10 & 15 & 65 & - & - & 1071 \\
\hline & 30 & 12 & 20 & 81 & - & - & 1074 \\
\hline & $60^{*}$ & 22 & 28 & 108 & - & - & 1066 \\
\hline \multirow[t]{4}{*}{1100} & 10 & 16 & 21 & 88 & 1137 & 1119 & 1160 \\
\hline & 20 & 28 & 37 & 137 & 1183 & 1172 & 1175 \\
\hline & 30 & 32 & 43 & 138 & 1168 & 1160 & 1147 \\
\hline & $60^{\star}$ & 38 & 48 & 184 & 1132 & 1106 & 1139 \\
\hline \multirow[t]{5}{*}{1200} & 6 & 19 & 26 & 105 & 1187 & 1189 & 1225 \\
\hline & 10 & 25 & 34 & 148 & 1191 & 1192 & 1241 \\
\hline & 20 & 34 & 50 & 207 & 1187 & 1198 & 1240 \\
\hline & 30 & 44 & 62 & 260 & 1194 & 1200 & 1244 \\
\hline & $60^{*}$ & 70 & 90 & 360 & 1209 & 1204 & 1241 \\
\hline \multirow[t]{3}{*}{1300} & 10 & 55 & 63 & 210 & 1294 & 1278 & 1300 \\
\hline & 20 & 77 & 91 & 294 & 1294 & 1282 & 1300 \\
\hline & $60^{*}$ & 115 & 140 & 502 & 1274 & 1266 & 1298 \\
\hline \multirow[t]{5}{*}{1400} & 3 & 46 & 67 & 161 & 1349 & 1376 & 1365 \\
\hline & 10 & 79 & 104 & 286 & 1346 & 1356 & 1357 \\
\hline & $10(w)$ & 100 & 131 & 328 & 1382 & 1394 & 1383 \\
\hline & 20 & 139 & 175 & 465 & 1381 & 1386 & 1385 \\
\hline & 30 & 152 & 197 & 532 & 1364 & 1372 & 1373 \\
\hline \multirow[t]{4}{*}{1500} & 3 & 82 & 146 & 275 & 1440 & 1516 & 1461 \\
\hline & 10 & 155 & 226 & 491 & 1453 & 1492 & 1466 \\
\hline & $10(w)$ & 200 & 299 & 640 & 1498 & 1548 & 1525 \\
\hline & $30^{*}$ & 327 & 425 & 835 & 1490 & 1511 & 1465 \\
\hline
\end{tabular}

* : these data are eliminated from the calculation for the average temperature. 
Table 6: contd.

\begin{tabular}{|c|c|c|c|c|c|c|c|}
\hline \multirow{2}{*}{$\begin{array}{c}\text { Nominal } \\
\text { Temp. } \\
\left({ }^{\circ} \mathrm{C}\right)\end{array}$} & \multirow{2}{*}{$\begin{array}{l}\text { Annelaing } \\
\text { Time (min) }\end{array}$} & \multicolumn{3}{|c|}{ Layer thickness $(\mu \mathrm{m})$} & \multicolumn{3}{|c|}{ Estimated Temperature $\left({ }^{\circ} \mathrm{C}\right)$} \\
\hline & & 1 & 11 & III & $I$ & II & IIII \\
\hline \multirow[t]{5}{*}{1600} & 1 & 88 & 175 & 277 & 1527 & 1643 & 1560 \\
\hline & 3 & 144 & 223 & 431 & 1539 & 1602 & 1562 \\
\hline & 6 & 192 & 327 & 582 & 1534 & 1617 & 1559 \\
\hline & $10^{\star}$ & 267 & 435 & - & 1551 & 1627 & - \\
\hline & $10^{*}(w)$ & 209 & 434 & 780 & 1566 & 1626 & 1575 \\
\hline \multirow[t]{6}{*}{1700} & 1 & 129 & 296 & 433 & 1598 & 1766 & 1670 \\
\hline & 1 & 117 & 265 & 360 & 1578 & 1738 & 1621 \\
\hline & 3 & 222 & 362 & 677 & 1622 & 1711 & 1676 \\
\hline & 3 & 188 & 376 & 618 & 1589 & 1720 & 1652 \\
\hline & 6 & 302 & 533 & 866 & 1622 & 1730 & 1659 \\
\hline & $10^{*}$ & 407 & 556 & 869 & 1634 & 1682 & 1598 \\
\hline
\end{tabular}

*: these data are eliminated from the calculation for the average temperature. 
Table 7: Average of estimated temperatures and corrected temperatures for the $\mathrm{UO}_{2} /$ Zircaloy reaction experiments in Ar.

\begin{tabular}{|c|c|c|c|c|}
\hline $\begin{array}{c}\text { Nominal Test } \\
\text { Temperature } \\
\left({ }^{\circ} \mathrm{C}\right)\end{array}$ & \multicolumn{2}{|c|}{ Average Estimated Temperature $\left.{ }^{\circ} \mathrm{C}\right)$} & $\begin{array}{c}\text { Corrected } \\
\text { Temperature } \\
\left({ }^{\circ} \mathrm{C}\right)\end{array}$ \\
\cline { 2 - 5 } & I & II & III & 1077 \\
1000 & 1163 & 1150 & 1077 & $1158^{*}$ \\
1100 & 1190 & 1195 & 1161 & $1208^{*}$ \\
1300 & 1294 & 1280 & 1238 & $1291^{*}$ \\
1400 & 1364 & 1377 & 1300 & $1364^{*}$ \\
1500 & 1464 & 1519 & 1370 & $1464^{* *}$ \\
1600 & 1533 & 1621 & 1484 & $1533^{*}$ \\
1700 & 1602 & 1733 & 1560 & $1602^{*}$ \\
\hline
\end{tabular}

* average of three estimated temperatures

* * only the estimated temperature for zone I was used (see page 7) 
Table 8: Regression constants calculated by the method of least squares for the $\mathrm{UO}_{2} /$ Zircaloy reaction kinetics data in $\operatorname{Ar}\left(x=a_{0}+a_{1} v_{t} ; a_{0}=0\right)$.

\begin{tabular}{|c|c|c|c|c|c|c|c|}
\hline \multirow{2}{*}{$\begin{array}{c}\text { Nominal Test } \\
\text { Temperature } \\
\left({ }^{\circ} \mathrm{C}\right)\end{array}$} & \multicolumn{2}{|c|}{$K_{p}(I)$} & \multicolumn{3}{c|}{$K_{p}(I I)$} & \multicolumn{3}{c|}{$K_{p}(I I I)$} & $\begin{array}{c}\text { Time Range } \\
\text { (min) }\end{array}$ \\
\cline { 2 - 8 } & KfK 3552 & corrected & $K f K 3552$ & corrected & KfK 3552 & corrected & $10 \sim 60$ \\
\hline 1000 & $1.06 \cdot 10-9$ & $1.05 \cdot 10-9$ & $2.13 \cdot 10-9$ & $2.11 \cdot 10-9$ & $3.50 \cdot 10-8$ & $3.46 \cdot 10-8$ & $10 \sim 60$ \\
1100 & $4.82 \cdot 10-9$ & $4.79 \cdot 10-9$ & $8.15 \cdot 10-9$ & $8.09 \cdot 10-9$ & $1.1 \cdot 10-7$ & $1.08 \cdot 10-7$ & $6 \sim 60$ \\
1200 & $1.19 \cdot 10-8$ & $1.17 \cdot 10-8$ & $2.16 \cdot 10-8$ & $2.13 \cdot 10-8$ & $3.61 \cdot 10-7$ & $3.57 \cdot 10-7$ & $10 \sim 60$ \\
1300 & $5.48 \cdot 10-8$ & $4.04 \cdot 10-8$ & $7.08 \cdot 10-8$ & $5.82 \cdot 10-8$ & $9.43 \cdot 10-7$ & $7.01 \cdot 10-7$ & $3 \sim 30$ \\
1400 & $1.49 \cdot 10-7$ & $1.34 \cdot 10-7$ & $2.37 \cdot 10-7$ & $2.26 \cdot 10-7$ & $1.77 \cdot 10-6$ & $1.59 \cdot 10-6$ & $3 \sim 30$ \\
1500 & $5.29 \cdot 10-7$ & $5.36 \cdot 10-7$ & $9.76 \cdot 10-7$ & $1.04 \cdot 10-6$ & $3.92 \cdot 10-6$ & $4.28 \cdot 10-6$ & $3 \sim 10$ \\
1600 & $1.25 \cdot 10-6$ & $1.21 \cdot 10-6$ & $2.92 \cdot 10-6$ & $2.77 \cdot 10-6$ & $1.03 \cdot 10-5$ & $7.85 \cdot 10-6$ & $1 \sim 20$ \\
1700 & $2.56 \cdot 10-6$ & $2.06 \cdot 10-6$ & $8.47 \cdot 10-6$ & $7.17 \cdot 10-6$ & $2.19 \cdot 10-5$ & $1.92 \cdot 10-5$ & $1 \sim 6$ \\
\hline
\end{tabular}

$K_{p}$ in $\mathrm{cm}^{2} / \mathrm{s}$ 


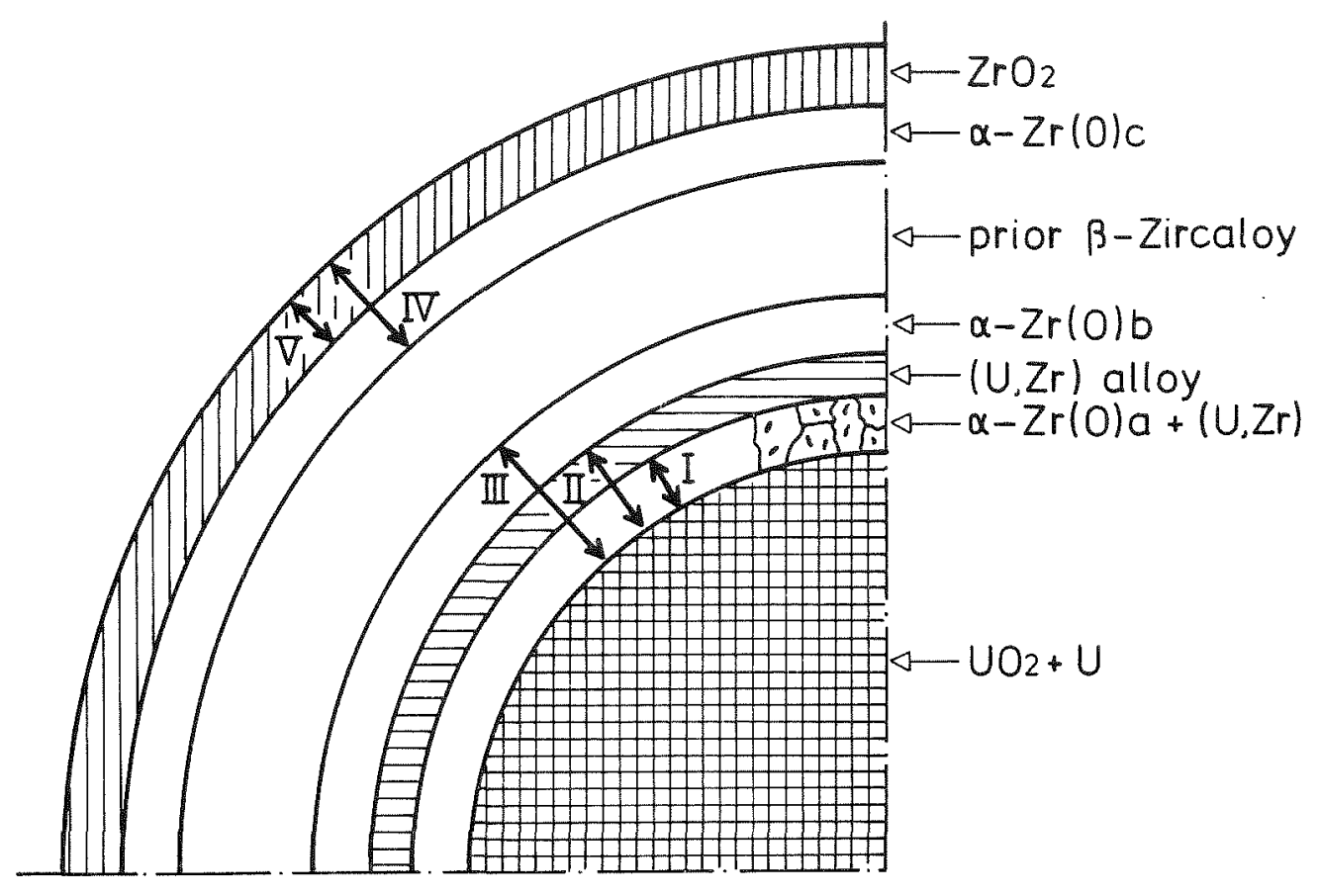

- Zone I : $\alpha$-Zr(O)a $+(U, Z r)$

- Zone II : Zone I + (U,Zr) alloy

- Zone III : Zone II $+\alpha-\operatorname{Zr}(0) b$

- Zone IV: $\quad \alpha-\mathrm{Zr}(\mathrm{O}) \mathrm{c}+\mathrm{ZrO} 2$

- Zone $\nabla: \quad \mathrm{ZrO}_{2}$

Fig. 1: Schematic illustration of the sequence of $\mathrm{UO}_{2} / Z$ ry reaction layers and the definition of the various reaction zones. 
1.

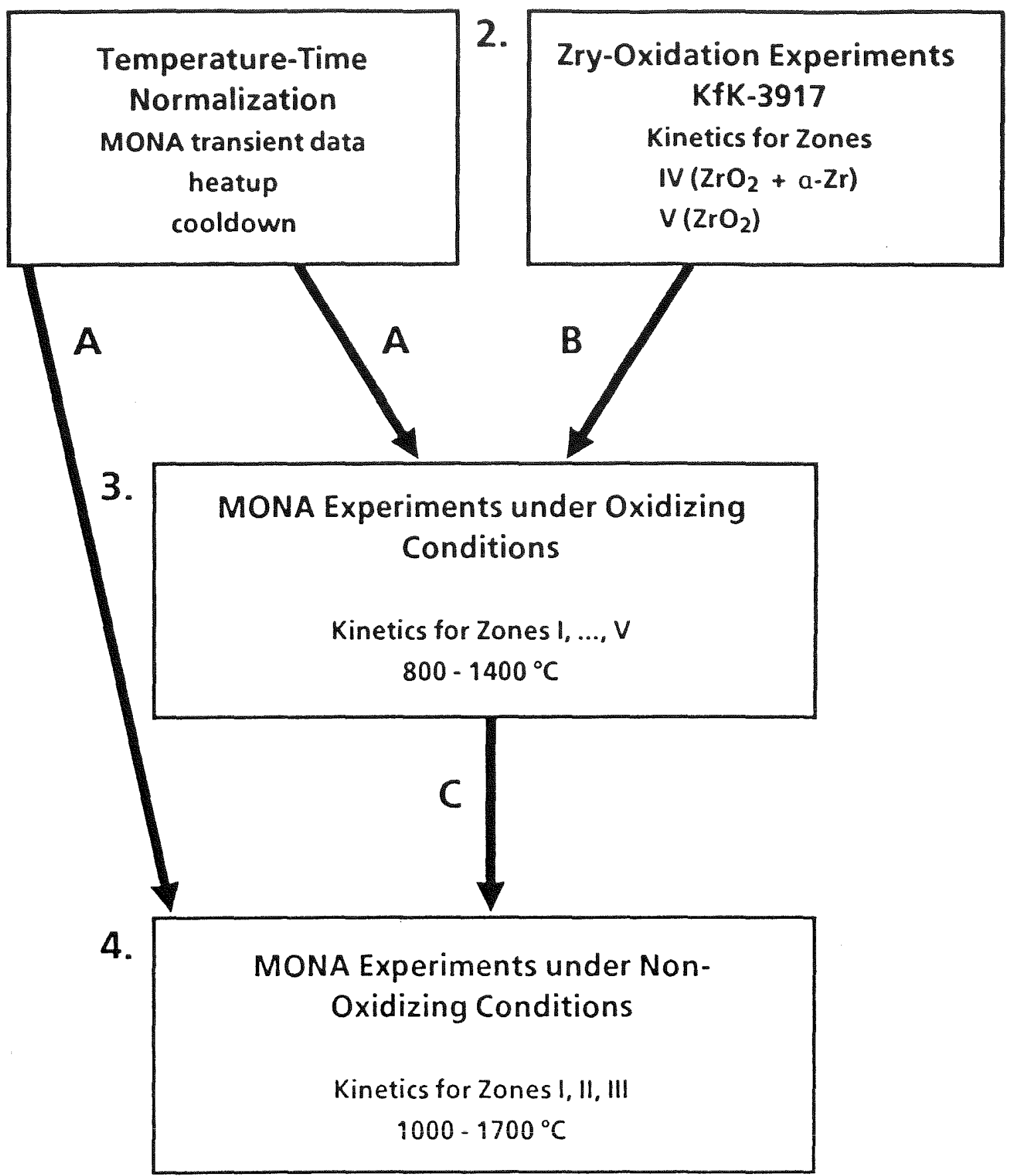

A: isothermal annealing time correction by a simple normalization method.

$\mathrm{B}$ : temperature correction based on the kinetics for zone $\mathrm{V}\left(\mathrm{ZrO}_{2}\right)$

C: temperature correction based on the obtained kinetics for zones I, II, III.

Fig.2: Sequence of the kinetics data correction for the $\mathrm{UO}_{2} /$ Zircaloy interaction experiments. 


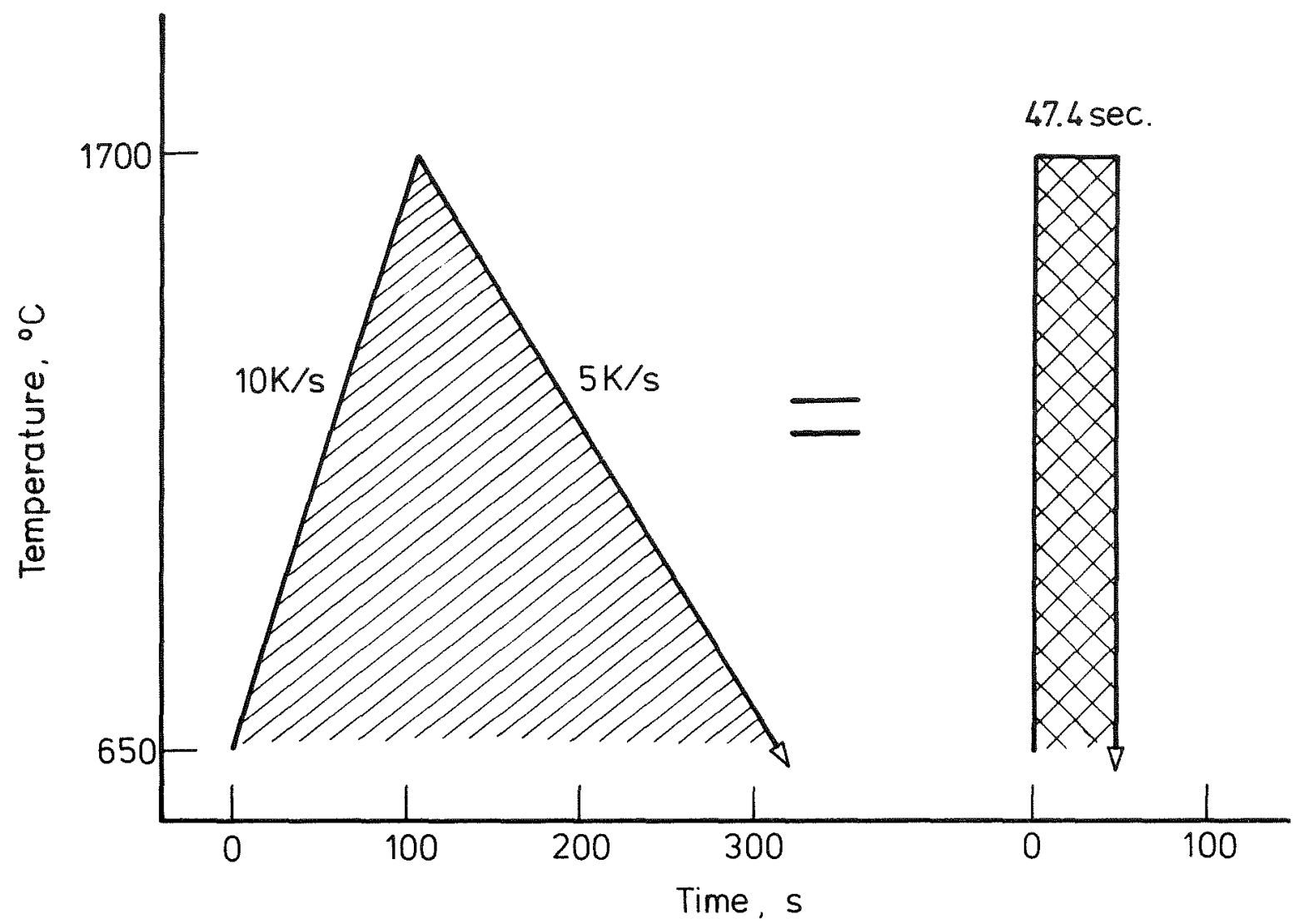

Fig. 3: Schematic illustration of the typical heat-up and cool-down rates in the $\mathrm{UO}_{2}$ /Zircaloy interaction experiments and its correction by an equivalent isothermal annealing time. 
Temperature, ${ }^{\circ} \mathrm{C}$

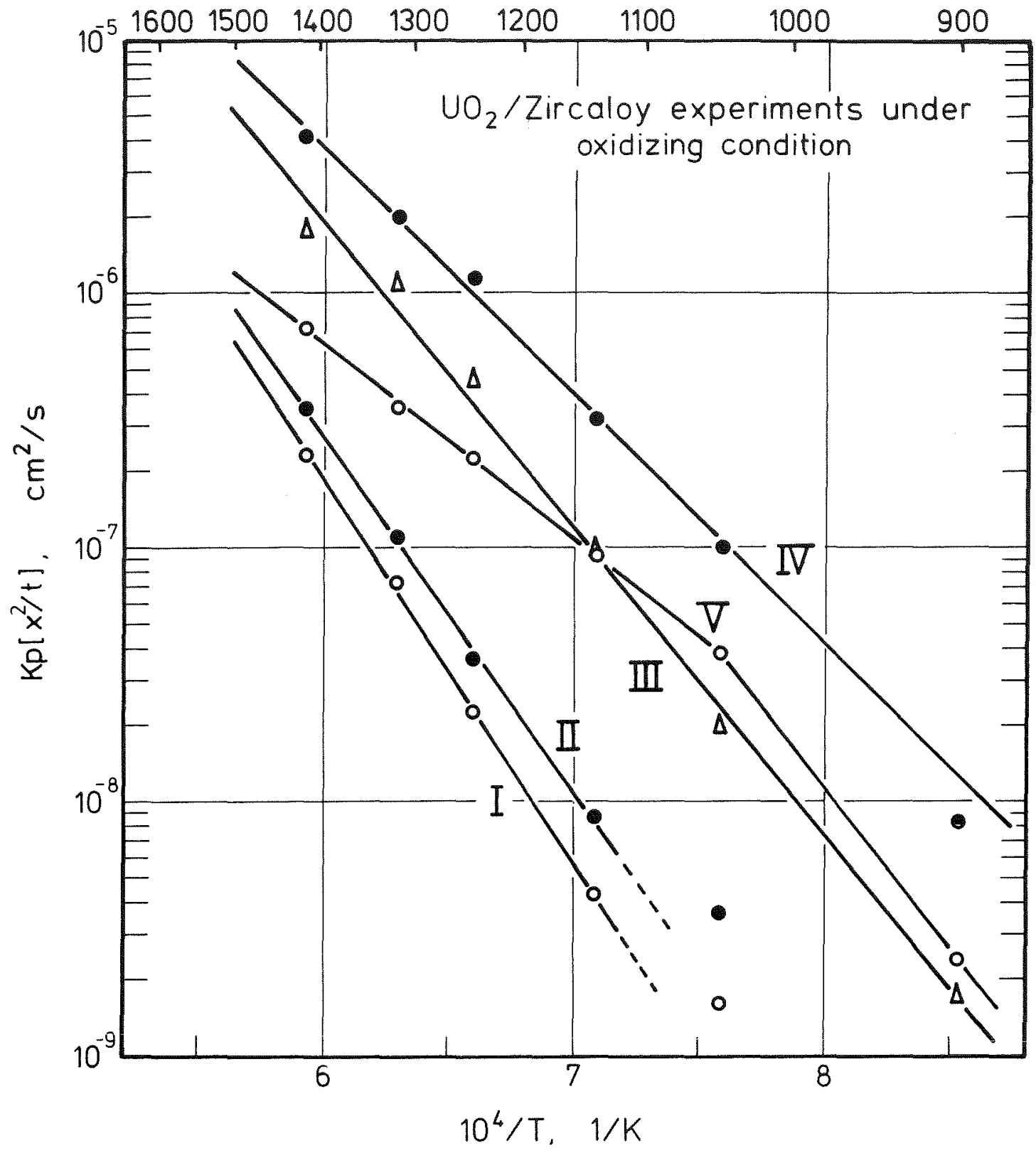

Fig.4: Arrhenius plot of the parabolic rate constants for the growth of the reaction zones $1-V$ in the $\mathrm{UO}_{2}$ /Zircaloy reaction experiments under oxidizing conditions. 
$-40-$

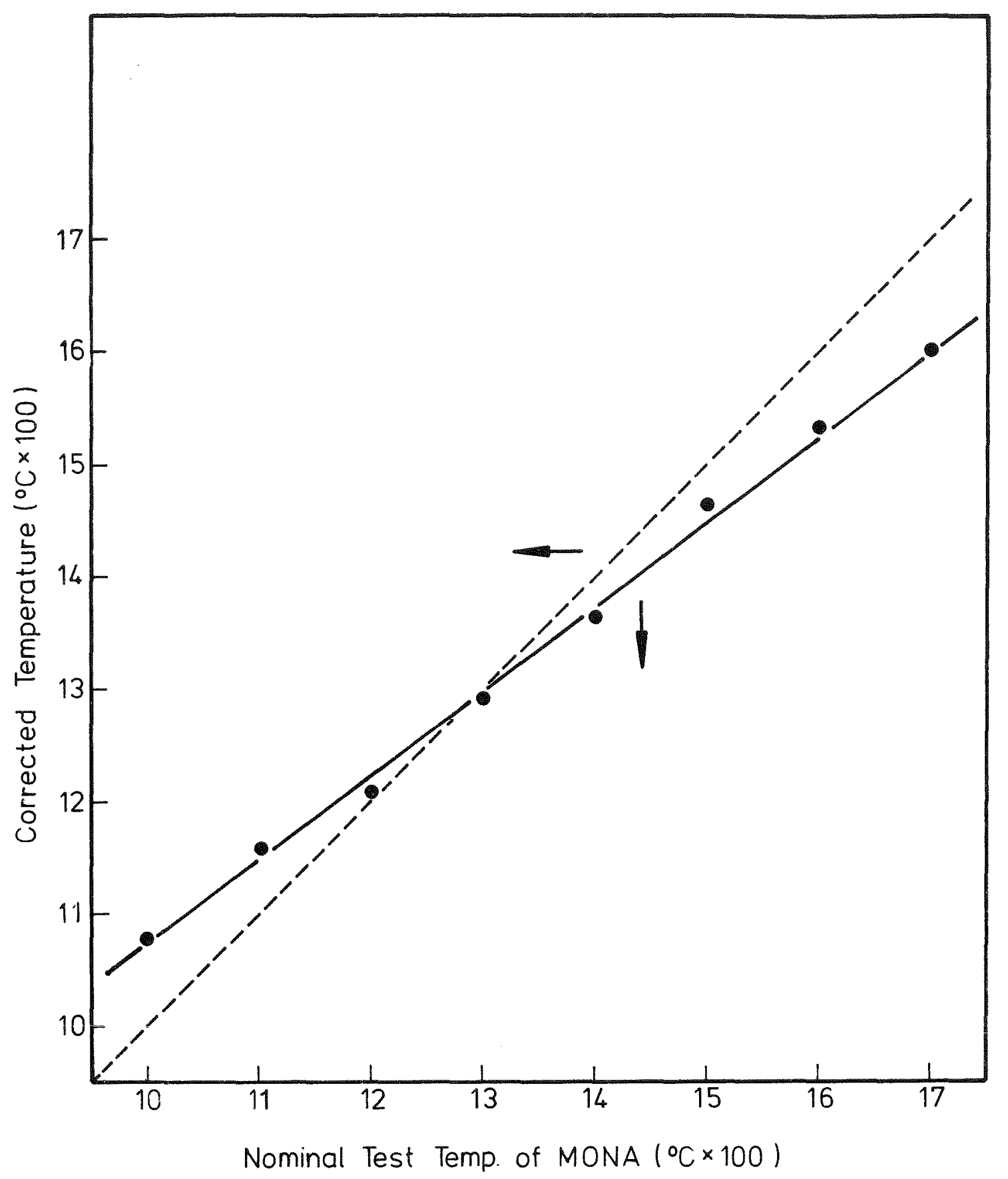

Fig. 5: Correlation between nominal test temperatures in the $\mathrm{UO}_{2} / \mathrm{Zry}$ reaction experiments in Ar and corrected temperatures. 


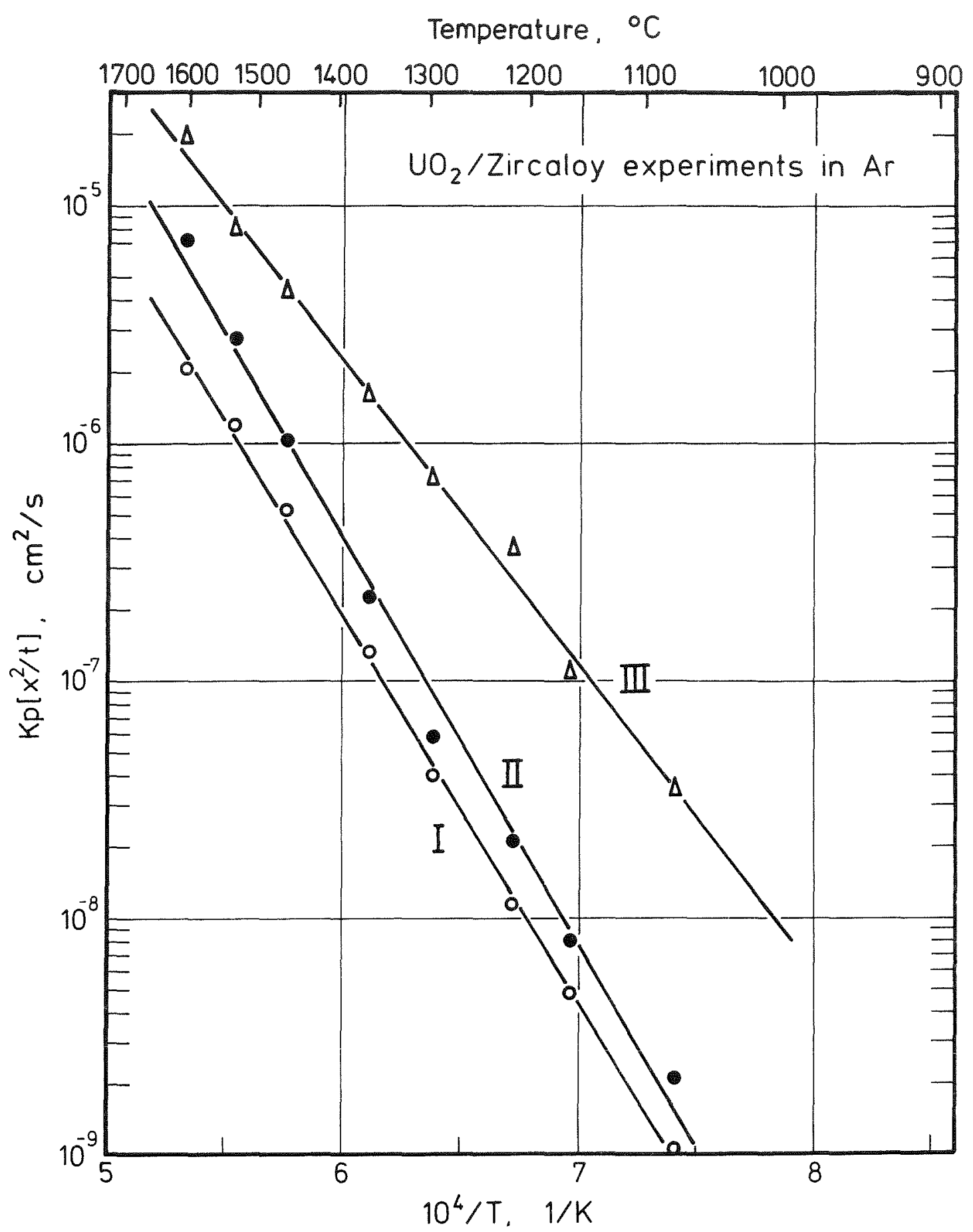

Fiq. 6: Arrhenius plot of the parabolic rate constants for the growth of zones 1 , II and III in the $\mathrm{UO}_{2}$ /Zircaloy interaction experiments in $\mathrm{Ar}$ (corrected data). 


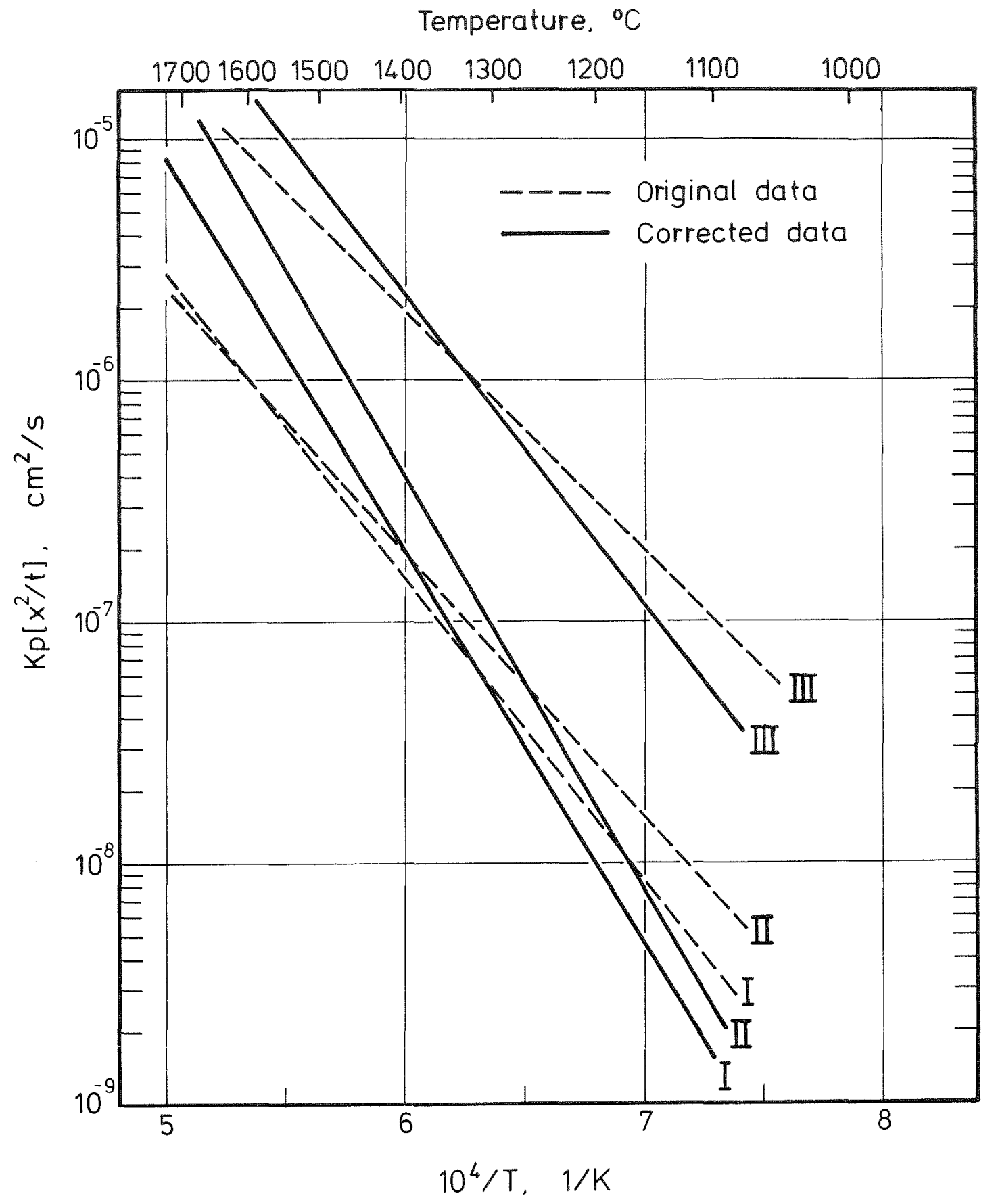

Fig. 7: Comparison of the previously determined and the corrected parabolic rate constants for the growth of zones 1,11 and 111 in the $\mathrm{UO}_{2}$ /Zircaloy interaction experiments in Ar. 


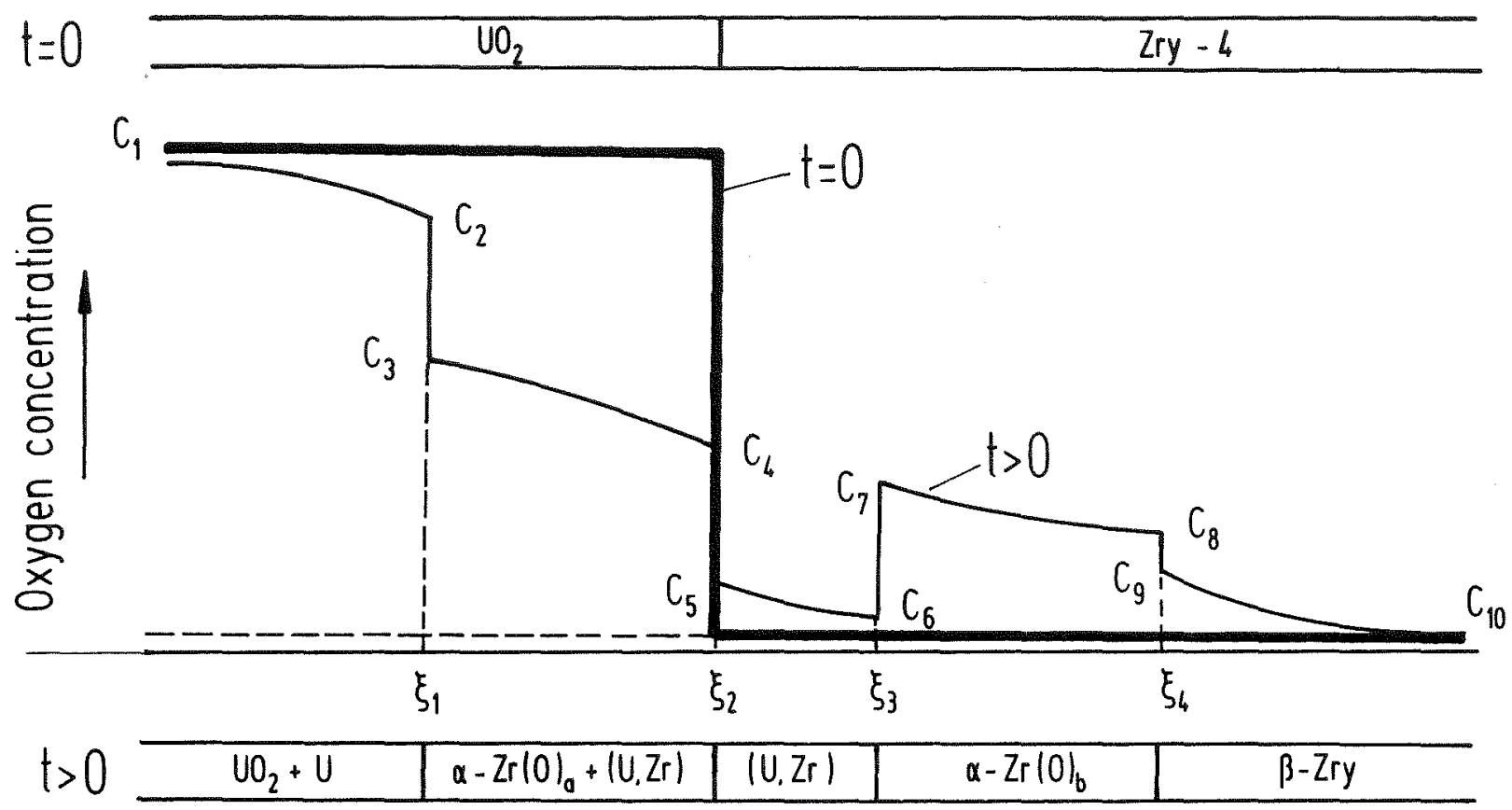

Fig. 8: At $t=0, \cup_{2}$ and Zircaloy are brought into solid contact (upper scheme). The oxygen concentration profile is indicated below by the bold line. After some annealing time $(t>0)$ several phases have formed (lower scheme) separated by moving interfaces $\xi_{1}, \xi_{3}$ and $\xi_{4}$. At every instant $\xi_{2}=0$; this is chosen as the origin of the coordinate system. 


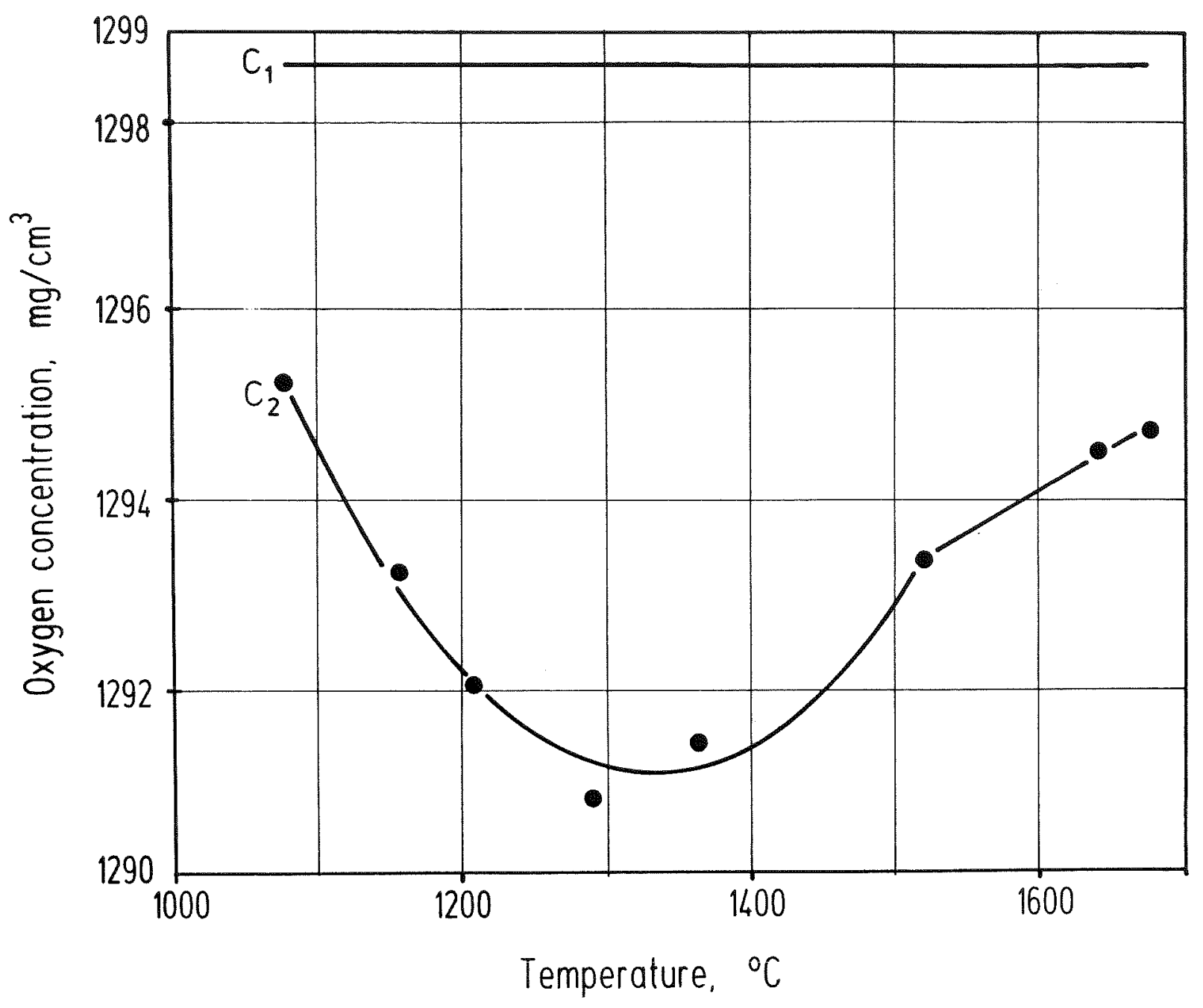

Fig. 9: Interface concentrations $C_{1}$ and $C_{2} . C_{1}$ is temperature independent and equal to $1298.6 \mathrm{mg} / \mathrm{cm}^{3}$ (eq. 4). The points represent the values of $\mathrm{C}_{2}$ employed in the calculations and the curve represents the function (16) which fits best to the points. 


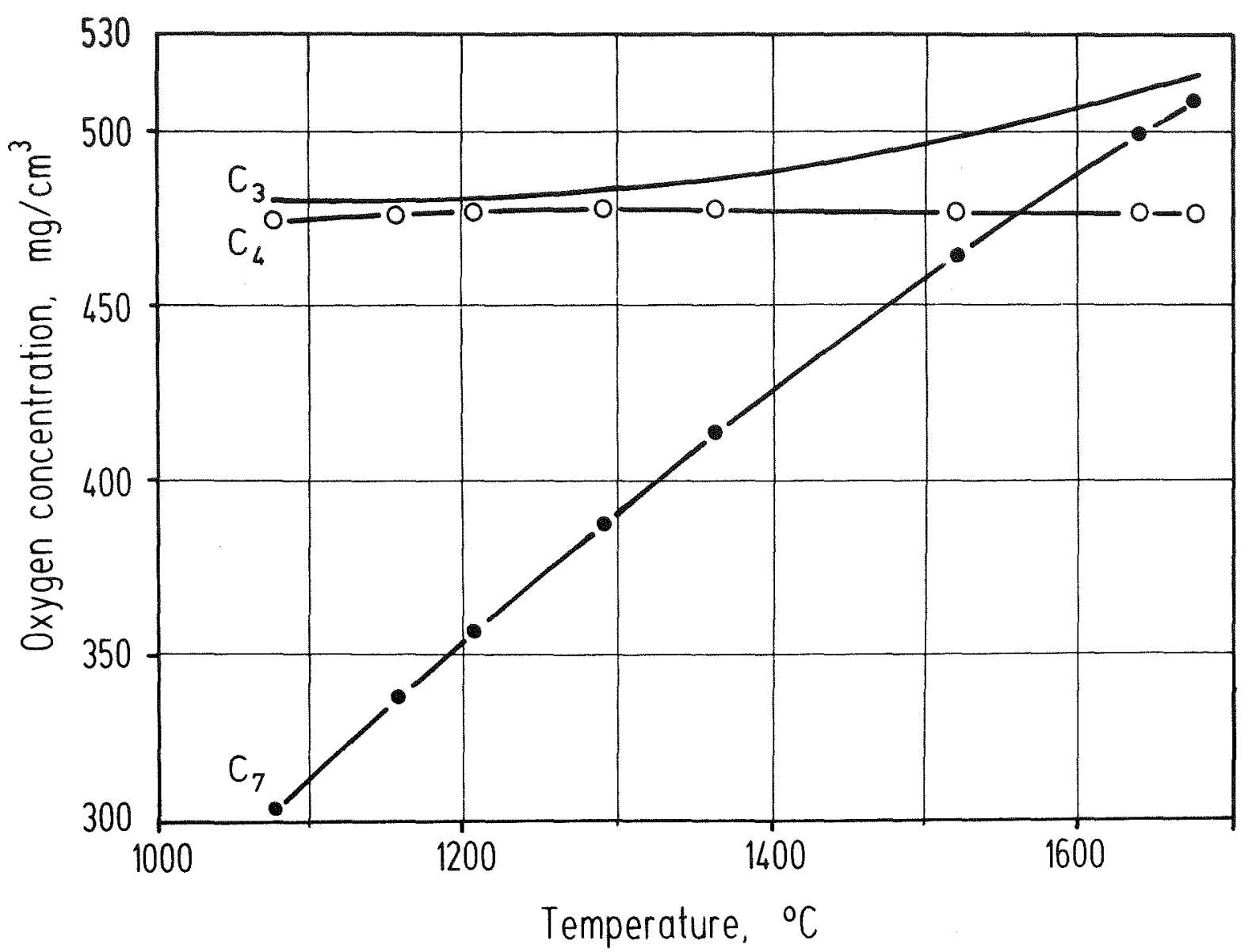

Fig. 10: Temperature dependence of the interface concentrations $C_{3}, C_{4}$ and $C_{7} . C_{3}$ is given by (7). The points represent the values of $C_{4}$ and $C_{7}$ used in the calculations and the curves represent the functions (17) and (19) which fit best to the points. 


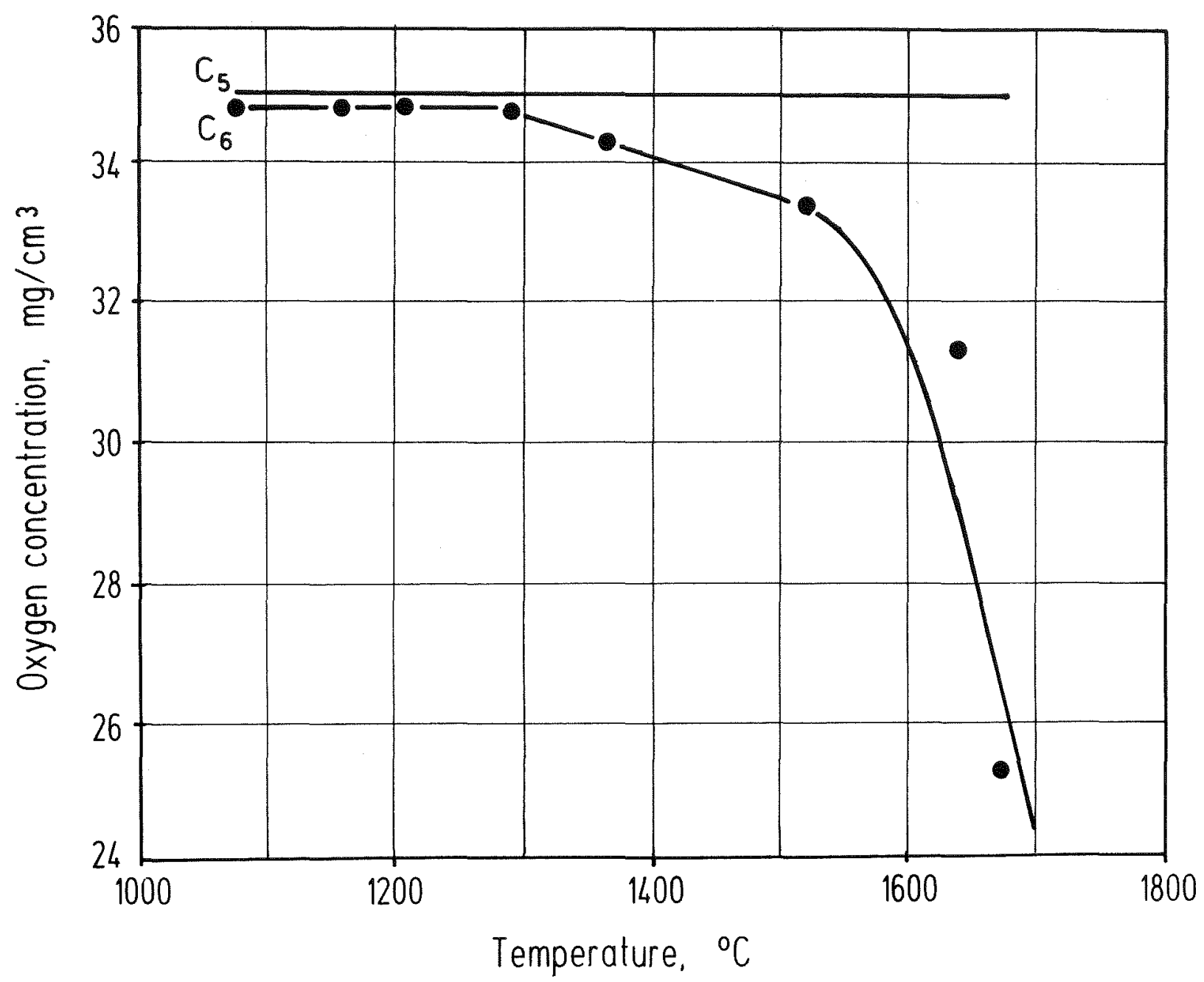

Fig. 11: Interface concentrations $C_{5}$ and $C_{6} . C_{5}$ is chosen temperature independent and equal to $35 \mathrm{mg} / \mathrm{cm}^{3}$. The points represent the values of $C_{6}$ used in the calculations and the curve represents the function (18) which fits best to the points. 


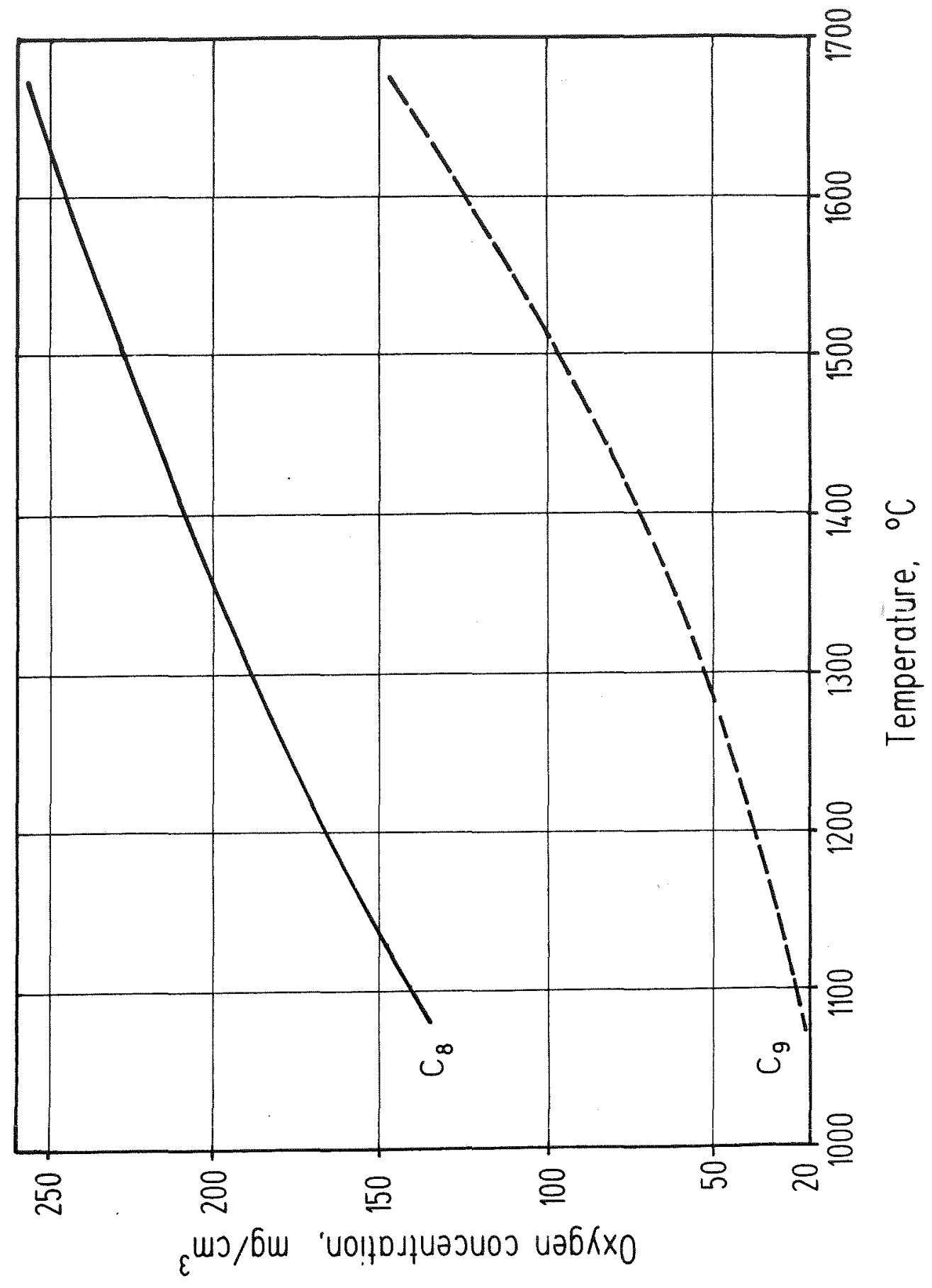

Fig. 12: Temperature dependence of the interface concentrations $C_{8}$ and $C_{9}$ given in (10). 


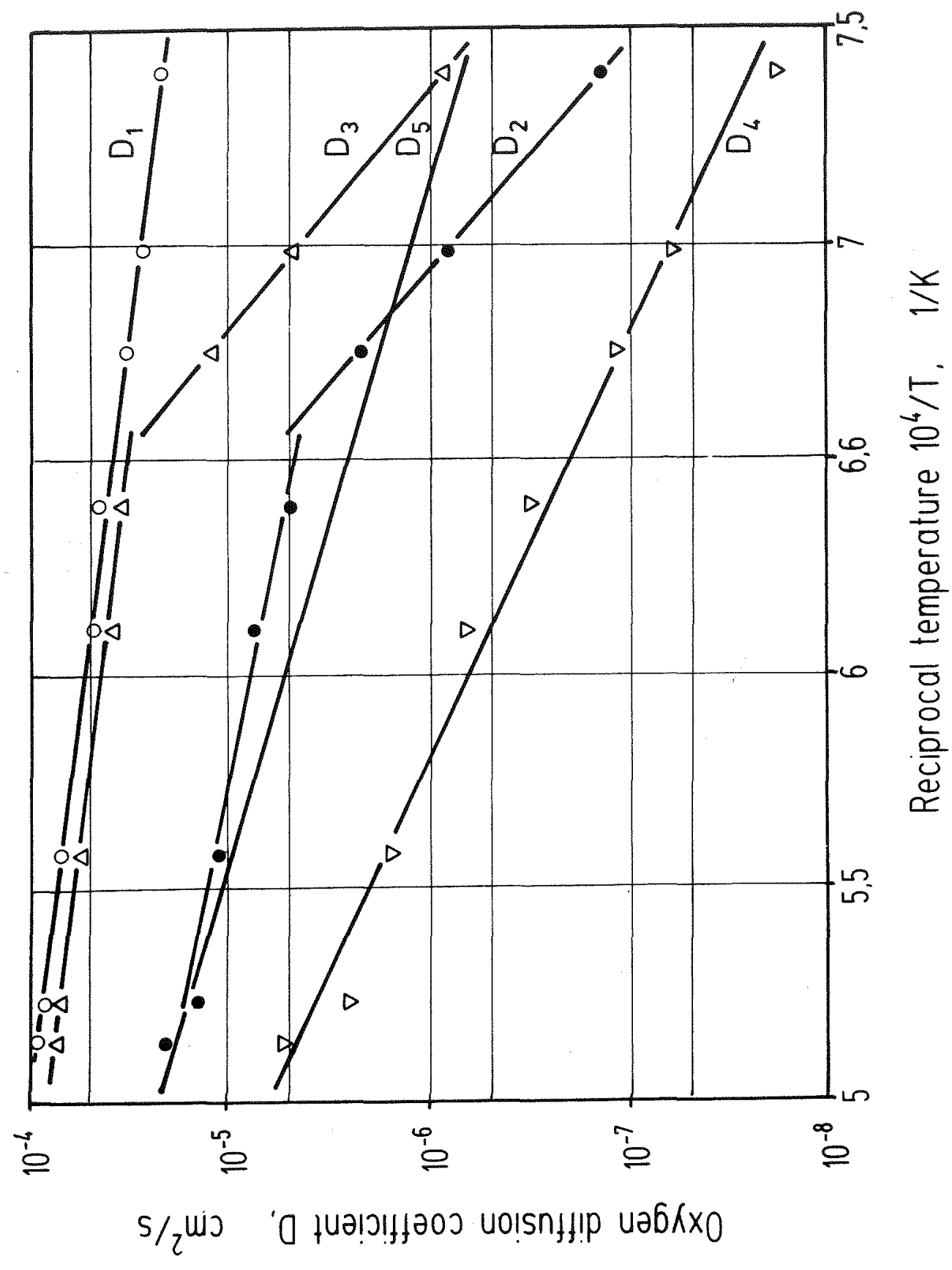

Fig. 13: Diffusion coefficients of oxygen in the five phases of the system. The points represent the solutions of eqs. $12-15$ when eqs. $4,7,10,16-19$ are entered as data. The lines represent $D_{5}$ (eq. 11) and the Arrhenius functions (20) which fit best to the points. 


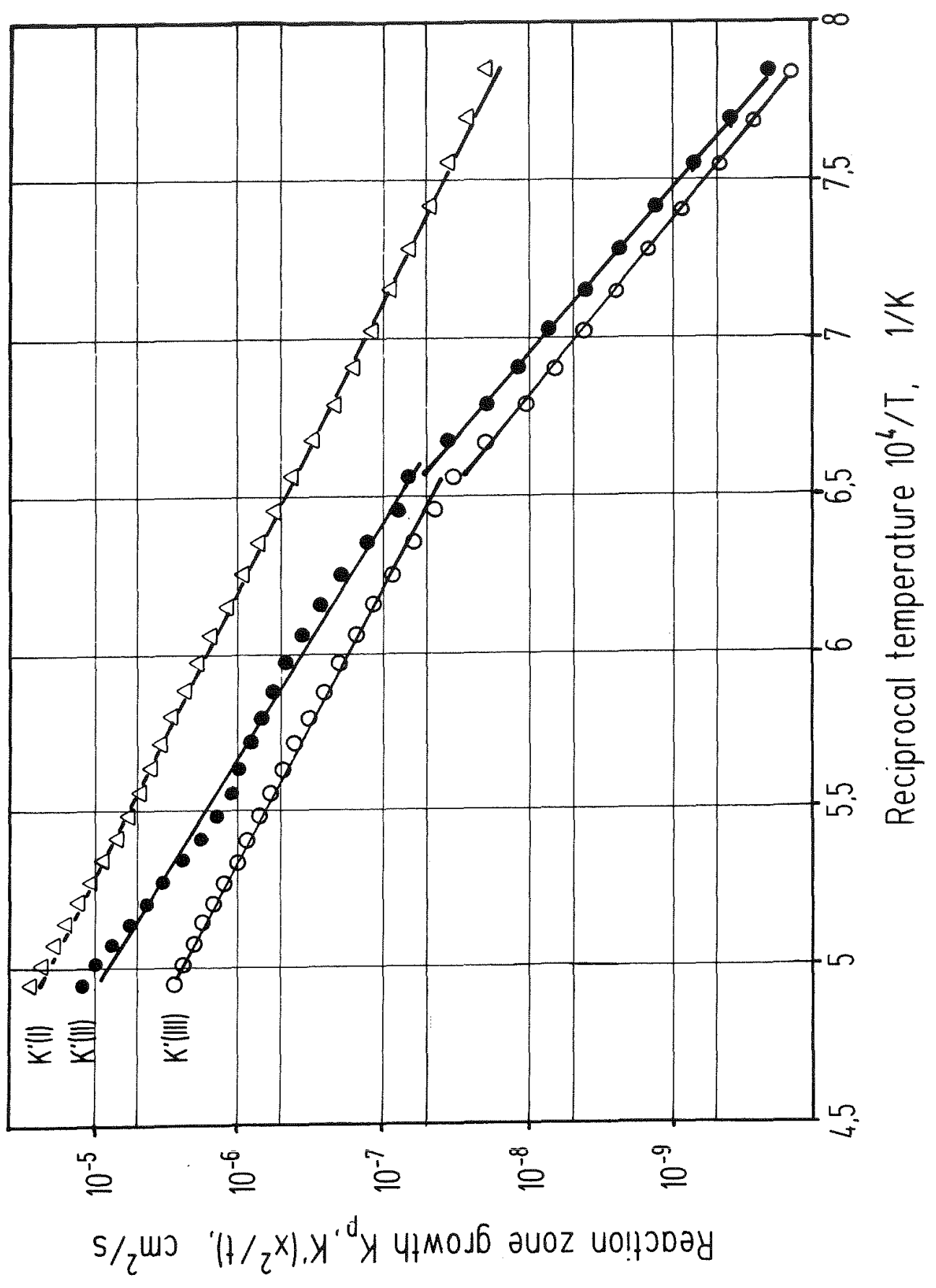

Fig. 14: Kinetic constants $K^{\prime}(1), K^{\prime}$ (II) and $K^{\prime}$ (III) for the growth of zone I, II and III, respectively. The points represent the solutions of eqs. $12-15$ taking the concentrations from eqs. 4, 7, 10,16-19 and the diffusion coefficients from eq. (20). The lines represent the Arrhenius functions (21) which fit best to the points. 


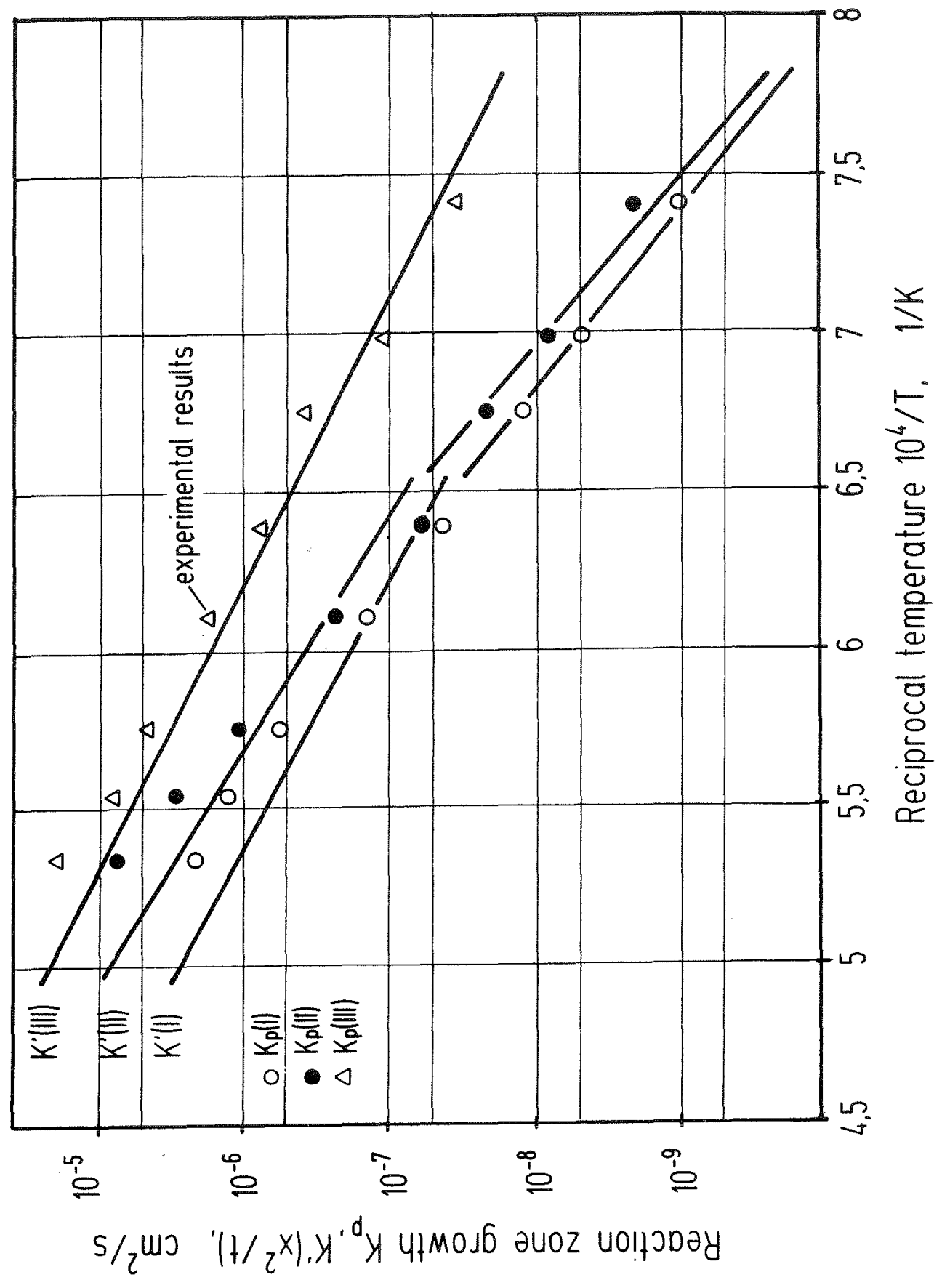

Fiq. 15: The points represent the experimentally determined kinetic constants $K_{p}$ (I), $K_{p}$ (II) and $K_{p}$ (III) for the growth of zones I, II and III, respectively. The lines representing eq. (21) are superimposed for comparison. 